\title{
Arquitectura estratigráfica, paleogeografía y proveniencia sedimentaria de las rocas cenozoicas del sur de Perú (Tacna, $18^{\circ} \mathrm{S}$ )
}

\author{
*Aldo A. Alván ${ }^{1}$, Yacory F. Bustamante ${ }^{1,2}$, Elvis A. Sánchez ${ }^{1}$, Mirian I. Mamani \\ ${ }^{1}$ Instituto Geológico Minero y Metalúrgico (INGEMMET), Dirección de Geología Regional, Av. Canadá No 1470, San Borja, Lima, Perú. \\ aalvan@ingemmet.gob.pe; esanchez@ingemmet.gob.pe \\ 2 Universidad Nacional de Cajamarca (UNC), Av. Atahualpa No 1050, Cajamarca, Perú. \\ yacory1@gmail.com \\ 3 Universidad Georg-August de Göttingen, Departamento de Geoquímica, Goldschmidtstrasse 1, 37077, Göttingen, Alemania. \\ mimahui@hotmail.com \\ * Filiación actual del primer autor: Universidad Nacional Mayor de San Marcos (UNMSM) E.P. Ingeniería Geológica. Av. Venezuela \\ cdra. 34, Lima 1, Perú. \\ aalvand@unmsm.edu.pe
}

RESUMEN. Las rocas cenozoicas en la provincia de Tacna $\left(18^{\circ} \mathrm{S}\right.$, sur de Perú) representan aproximadamente $600 \mathrm{~m}$ de espesor estratigráfico con las formaciones Sotillo (Paleoceno), Moquegua Inferior (Eoceno), Moquegua Superior (Oligoceno), Huaylillas (Mioceno) y Millo (Plioceno), y conforman el relleno sedimentario de la extensa cuenca Moquegua. En las rocas de las tres últimas formaciones recién nombradas se definen nueve facies sedimentarias y cinco elementos arquitecturales. Su asociación sugiere la existencia de un antiguo sistema fluvial trenzado altamente canalizado y multilateral, con aumento de intercalaciones piroclásticas y conglomerádicas hacia el tope. Los espectros de minerales pesados caracterizan a cada una de estas unidades, por ejemplo, las rocas de la Formación Moquegua Superior son ricas en granates, titanitas y circones, mientras que las de las formaciones Huaylillas y Millo lo son en clinopiroxenos. Este arreglo mineral permite correlacionar la estratigrafía de las secuencias aflorantes con lo interpretado en el subsuelo de Tacna (por medio del muestreo y el estudio de pozos de perforación), lo que esboza un nuevo esquema estratigráfico y un complejo de bloques limitados por fallas normales que en algunos casos están basculados. La mineralogía sedimentaria sugiere, además, que las rocas de la cordillera Occidental fueron los principales aportantes de detritos a la cuenca Moquegua en Tacna. En tal contexto, los sedimentos de la Formación Moquegua Superior provienen principalmente de la erosión de las rocas del Complejo Basal de la Costa (CBC, Proterozoico), Grupo Ambo (Carbonífero) y la Formación Junerata/Chocolate (Jurásico Inferior). La Formación Huaylillas es una unidad volcanosedimentaria, la cual deriva casi exclusivamente del volcanismo Huaylillas (Mioceno) y parcialmente de la denudación del Grupo Toquepala (Cretácico Superior), y contrasta con la subyacente Formación Moquegua Superior por su mineralogía y sus facies. Finalmente, los detritos de la Formación Millo derivaron mayormente de la denudación de las rocas de la Formación Barroso (Plioceno) y resaltan de las subyacentes unidades por sus notorias facies conglomerádicas. 


\begin{abstract}
Stratigraphic architecture, paleogeography and provenance of the Cenozoic sedimentary rocks in southern Perú (Tacna, $\left.\mathbf{1 8}^{\circ} \mathrm{S}\right)$. The Cenozoic rocks lying in the Province of Tacna $\left(18^{\circ} \mathrm{S}\right)$, southern Perú, represent approximately $600 \mathrm{~m}$ of stratigraphic thickness. This stacking groups the Sotillo (Paleocene), Moquegua Inferior (Eocene), Moquegua Superior (Oligocene), Huaylillas (Miocene) and Millo formations (Pliocene), and these are the sedimentary fill of the Moquegua Basin. The sediments of the three latter formations are organized into nine sedimentary facies and five architectural elements. Their facies associations suggest the existence of an ancient highly channelized multi-lateral fluvial braided system, with upward increase of pyroclastic and conglomeratic depositions. The heavy mineral spectra make each lithostratigraphic unit unique and distinguishable, being the sediments of the Moquegua Superior Formation rich in garnets, titanites and zircons; while the sediments of the Huaylillas and Millo formations in clinopyroxenes. This mineral arrangement becomes an excellent tool for stratigraphic correlations between outcrops and subsurface stratigraphy (by means of well cores studies) and allow to sketch out a new stratigraphic framework and a complex of rocky blocks bounded by normal faults, often tilted. The sediment mineralogy also suggests that the rocks conforming the Western Cordillera were the main source of sediments for the Moquegua Basin in Tacna. In this context, the detritus of the Moquegua Superior Formation derives mainly from the erosion of the rocks forming the Coastal Basal Complex (Proterozoic), the Ambo Group (Carboniferous) and the Junerata/Chocolate Formation (Early Jurassic). The Huaylillas Formation is a pyroclastic and sedimentary unit which components derived mainly from the Huaylillas volcanism (Miocene) and partly from the denudation of the Toquepala Group (Late Cretaceous). The Huaylillas Formation widely contrasts to the underlying Moquegua Superior Formation due its mineralogy and facies. Finally, the detritus of the Millo Formation derived mostly from the rocks forming the Barroso Formation (Pliocene), and their facies represent a higher contrast in relation to the underlying units due its notorious conglomerate facies.
\end{abstract}

Keywords: Central Andes, Tacna, Cenozoic, Sediment provenance.

\section{Introducción}

De acuerdo con Jordan et al. (1983) y Oncken et al. (2006), el oroclino de los Andes Centrales $\left(15-26^{\circ} \mathrm{S}\right)$ (Fig. 1A) en el suroeste de Perú está representado por las cordilleras Occidental y la de la Costa (Bellido, 1969), las cuales están compuestas por rocas proterozoicas, paleozoicas y mesozoicas (Palacios y Castillo, 1983; Palacios et al., 1993) (ver Sección 3.1 para más información). Según GregoryWodzicki (2000), Mahlburg-Kay et al. (2005), Garzione et al. (2008) y Oncken et al. (2006), estas rocas estuvieron sometidas a ciertos patrones espaciales de deformación, i.e., acortamiento, levantamiento y exhumación, en respuesta a variaciones en la velocidad y ángulo de convergencia entre las placas de Nazca y Sudamericana durante el proceso de subducción que afecta al margen andino de Sudamérica. Este estudio considera que tales mecanismos constituyen un control de primer orden en el relleno sedimentario de las cuencas de antearco del Sur de Perú y norte de Chile durante el intervalo Eoceno-Plioceno y su deformación (Fig. 1B), similar a lo propuesto por numerosos autores para las cuencas sedimentarias Moquegua y Azapa (e.g., Petersen, 1958; Salas et al., 1966; Marocco et al., 1985; Wörner et al., 2002; Decou et al., 2011; Wotzlaw et al., 2011; entre otros).

Este trabajo se centra en el relleno sedimentario de la cuenca Moquegua en el área de la provincia de
Tacna, sur de Perú $\left(18^{\circ} \mathrm{S}\right)$, precisamente donde la cordillera de la Costa tiene escasa presencia (Fig. 1C). El objetivo es entender los procesos sedimentarios acaecidos durante la transición Paleógeno-Neógeno en esta área; en particular, determinar la fuente de los sedimentos que rellenan la cuenca y proveer un marco cronoestratigráfico consistente que permita predecir la extensión lateral de estos depósitos en el subsuelo del área de Tacna. Para este fin, se toma especial consideración en las rocas de las formaciones Moquegua Superior (Oligoceno), Huaylillas (Mioceno) y Millo (Plioceno) (Fig. 2), debido a que son las unidades más abundantes y representativas de la cuenca sedimentaria Moquegua en la provincia de Tacna.

\section{Metodología}

Los procedimientos utilizados en este estudio comprenden (i) cartografiado geológico local (ii) análisis de facies sedimentarias (incluye identificación de elementos arquitecturales), (iii) logueo y muestreo de testigos de pozos de perforación del subsuelo de Tacna, (iv) análisis de minerales pesados (Tabla 1), el cual está basado en los parámetros sugeridos por Mange y Maurer (1992) y Mange et al. (2003), y (v) geocronología (U-Th)/He y U-Pb en apatitos y circones detríticos de sucesiones volcanosedimentarias con el objetivo de establecer la edad de depositación del material sedimentario original (Reiners et al., 2005; 

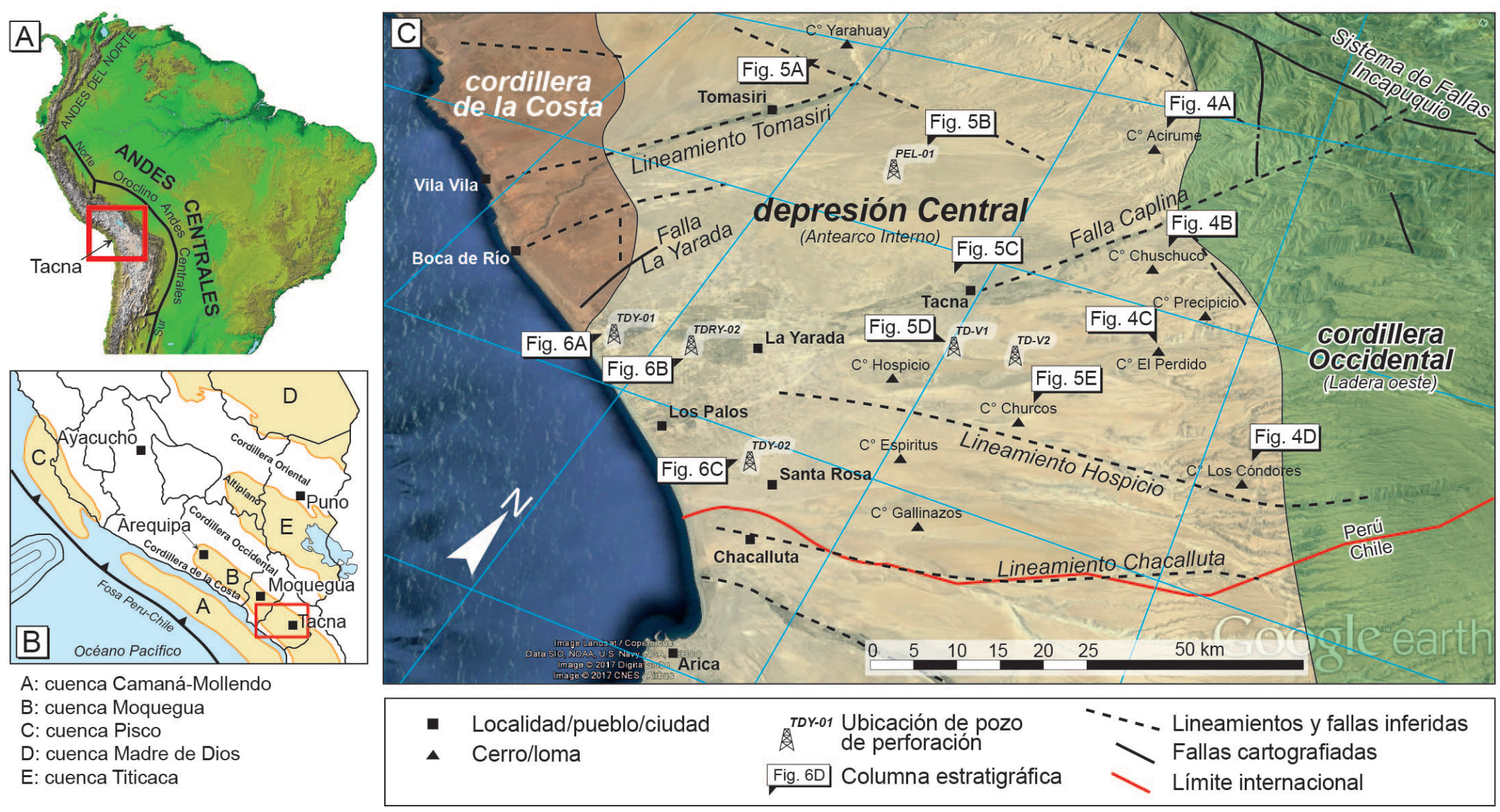

A: cuenca Camaná-Mollendo

B: cuenca Moquegua

C: cuenca Pisco

D: cuenca Madre de Dios

E: cuenca Titicaca

- Cerro/loma

Fig. 6D Columna estratigráfica

FIG. 1. Ubicación de la zona de estudio. A. Posición y división de los Andes de acuerdo con Sempere y Jacay (2008). B. Posición de la Cuenca sedimentaria Moquegua con relación a las demás cuencas sedimentarias cenozoicas del sur de Perú (polígonos de color amarillo claro, tomado de PERUPETRO, 2003). C. Vista en perspectiva de las unidades geomorfológicas involucradas en este estudio, i.e., cordillera de la Costa (en marrón claro), depresión Central (en color amarillo claro) y la ladera oeste de la cordillera Occidental (en color verde claro). Se enmarca el área de estudios en cuadro rojo. Las líneas punteadas y continuas negras representan fallas asumidas y cartografiadas, respectivamente. 


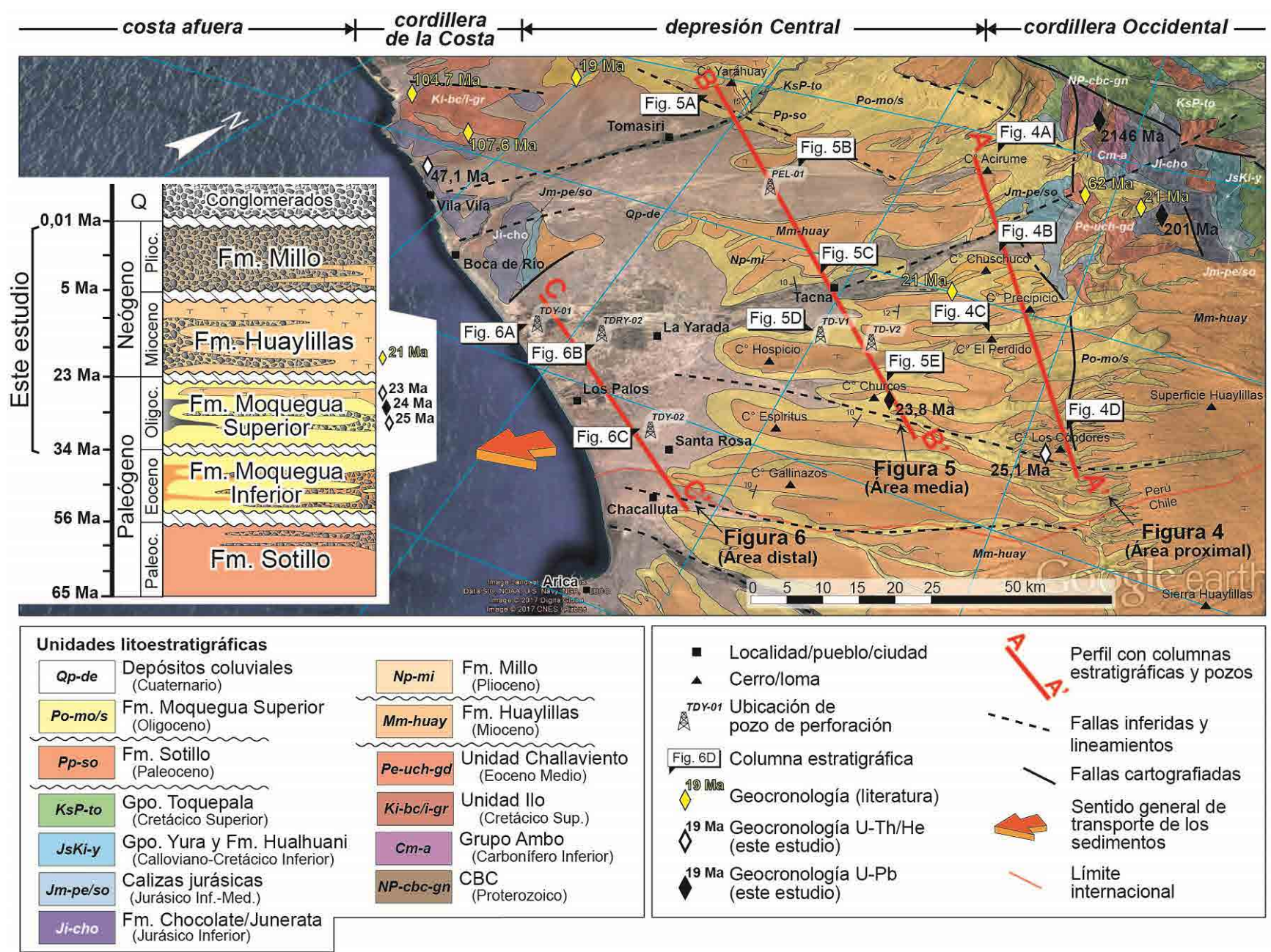

FIG. 2. Mapa geológico integrado de la zona de estudios (visto en perspectiva), provincia de Tacna. La geología base fue tomada de Monge y Cervantes (2000) y Sánchez et al. (2000) y posteriormente actualizada por Acosta et al. (2011). Se cuenta con siete columnas estratigráficas y cinco testigos de pozo de perforación (elaborados por el Proyecto Especial Tacna, PET en la década del 2000) que se analizan en este estudio. Las líneas rojas representan a las secciones A-A', B-B' y C-C', que indican la disposición de las columnas estratigráficas y de los pozos de perforación. Véase las figuras 4,5 y 6 para mayores detalles. 
TABLA 1. MUESTRAS COLECTADAS Y PROCESADAS PARA EL ANÁLISIS DE MINERALES PESADOS.

\begin{tabular}{|c|c|c|c|c|c|c|c|c|c|}
\hline Muestra & Unidad geológica & Long. & Lat. & H (m s.n.m.) & Litología & Granos & Ubicación & Condición & $\begin{array}{l}\text { Prof. } \\
\text { (m) }\end{array}$ \\
\hline GR41A-16-270 & Unidad Intrusiva Challaviento & 387.793 & 8.053 .537 & 3.176 & Granodiorita & 316 & Guacano Chico & Afloramiento & - \\
\hline GR41A-16-302 & Unidad Intrusiva Challaviento & 391.226 & 8.027 .875 & 2.169 & Granodiorita & 350 & Cerro La Mina & Afloramiento & - \\
\hline GR41A-16-301 & Unidad Intrusiva Challaviento & 388.135 & 8.026 .316 & 1.855 & Granodiorita & 300 & Cerro San Francisco & Afloramiento & - \\
\hline GR41A-16-296 & Grupo Toquepala & 396.919 & 8.046 .997 & 3.304 & Andesita & 281 & Cerro Chinchillane & Afloramiento & - \\
\hline GR41A-16-269 & Grupo Toquepala & 389.105 & 8.054 .823 & 3.264 & Andesita & 375 & Guacano Chico & Afloramiento & - \\
\hline GR41A-15-47 & Grupo Yura y Fm. Hualhuani & 382.384 & 8.025 .906 & 1.554 & Arenisca cuarzosa & 259 & Calientes & Afloramiento & - \\
\hline GR41A-15-98 & Grupo Yura y Fm. Hualhuani & 404.623 & 8.034 .988 & 3.994 & Arenisca cuarzosa & 263 & Palca & Afloramiento & - \\
\hline GR41A-15-101 & Grupo Yura y Fm. Hualhuani & 405520 & 8.035 .493 & 4.077 & Arenisca cuarzosa & 293 & Palca & Afloramiento & - \\
\hline GR41A-15-95 & Grupo Yura y Fm. Hualhuani & 404.687 & 8.033 .534 & 3.915 & Arenisca cuarzosa & 371 & Palca & Afloramiento & - \\
\hline GR41A-15-93 & Grupo Yura y Fm. Hualhuani & 404.180 & 8.035 .615 & 3.671 & Arenisca cuarzosa & 366 & Palca & Afloramiento & - \\
\hline GR41A-15-22 & Formación Chocolate & 303.788 & 8.009 .874 & 647 & Andesita & 314 & Puerto Grau & Afloramiento & - \\
\hline GR41A-15-74 & Formación Chocolate & 313.867 & 7.999 .920 & 2 & Andesita & 313 & Vila Vila & Afloramiento & - \\
\hline GR41A-15-72 & Formación Chocolate & 316.505 & 7.997 .657 & 1 & Andesita & 338 & Vila Vila & Afloramiento & - \\
\hline GR41A-15-68 & Grupo Ambo & 386.399 & 8.049 .582 & 2.896 & Arenisca cuarzosa & 298 & Guacano Chico & Afloramiento & - \\
\hline GR41A-15-67 & Complejo Basal de la Costa & 387.069 & 8.050 .180 & 2.988 & Gneis & 336 & Guacano Chico & Afloramiento & - \\
\hline GR41A-16-297 & Formación Millo & 361.798 & 8.005 .110 & 556 & Arenisca & 268 & Cerro Magollo & Afloramiento & - \\
\hline GR41A-16-38 & Formación Millo & 366.377 & 8.009 .915 & 739 & Arenisca & 256 & Alto de la Alianza & Afloramiento & - \\
\hline GR41A-16-298 & Formación Millo & 362.486 & 8.005 .419 & 520 & Arenisca & 261 & Cerro Magollo & Afloramiento & - \\
\hline GR41A-16-06 & Formación Huaylillas & 384.280 & 8.019 .635 & 1.572 & Arenisca & 244 & Cerro Chuschuco & Afloramiento & - \\
\hline GR41A-16-05 & Formación Huaylillas & 384.168 & 8.019 .578 & 1.607 & Arenisca & 279 & Cerro Chuschuco & Afloramiento & - \\
\hline GR41A-16-02 & Formación Huaylillas & 382.071 & 8.017.374 & 1.251 & Arenisca & 281 & Cerro Chuschuco & Afloramiento & - \\
\hline GR41A-16-01 & Formación Huaylillas & 382.083 & 8.017 .333 & 1.240 & Arenisca & 259 & Cerro Chuschuco & Afloramiento & - \\
\hline GR41A-16-294 & Formación Huaylillas & 375.847 & 8.034 .954 & 1.958 & Arenisca & 283 & Cerro Acirume & Afloramiento & - \\
\hline GR41A-16-59 & Formación Huaylillas & 342.198 & 9.036 .049 & 957 & Arenisca & 286 & Cerro Alto Grande & Afloramiento & - \\
\hline
\end{tabular}




\begin{tabular}{|c|c|c|c|c|c|c|c|c|c|}
\hline Muestra & Unidad geológica & Long. & Lat. & H (m s.n.m.) & Litología & Granos & Ubicación & Condición & $\begin{array}{c}\text { Prof. } \\
\text { (m) }\end{array}$ \\
\hline GR41A-16-57 & Formación Huaylillas & 342.371 & 8.036 .355 & 783 & Arenisca & 320 & Cerro Alto Grande & Afloramiento & - \\
\hline GR41A-16-13 & Formación Moquegua Superior & 371.855 & 7.990 .275 & 526 & Arenisca & 273 & Cerro Churcos & Afloramiento & - \\
\hline GR41A-16-177 & Formación Moquegua Superior & 385.694 & 8.020 .138 & 1.401 & Arenisca & 293 & Cerro Chuschuco & Afloramiento & - \\
\hline GR41A-16-176 & Formación Moquegua Superior & 385.785 & 8.020 .501 & 1.478 & Arenisca & 262 & Cerro Chuschuco & Afloramiento & - \\
\hline GR41A-16-08 & Formación Moquegua Superior & 384.795 & 8.020 .038 & 1.482 & Arenisca & 295 & Cerro Chuschuco & Afloramiento & - \\
\hline GR41A-16-07 & Formación Moquegua Superior & 384.631 & 8.019 .835 & 1.476 & Arenisca & 323 & Cerro Chuschuco & Afloramiento & - \\
\hline GR41A-16-10 & Formación Moquegua Superior & 371.381 & 7.990 .112 & 389 & Arenisca & 294 & Cerro Churcos & Afloramiento & - \\
\hline GR41A-16-09 & Formación Moquegua Superior & 371.302 & 7.990 .083 & 372 & Arenisca & 269 & Cerro Churcos & Afloramiento & - \\
\hline GR41A-16-263 & Formación Moquegua Superior & 375.650 & 8.035 .168 & 1.063 & Arenisca & 293 & Cerro Acirume & Afloramiento & - \\
\hline GR41A-16-261 & Formación Moquegua Superior & 390.953 & 7.997 .713 & 1.004 & Arenisca & 273 & Cerro Cubeta & Afloramiento & - \\
\hline GR41A-16-292 & Formación Moquegua Superior & 375.635 & 8.035 .455 & 1.776 & Arenisca & 272 & Cerro Acirume & Afloramiento & - \\
\hline GR41A-16-63 & Formación Millo & 346.914 & 7.984 .783 & 62 & Arenisca & 264 & Los Palos & Pozo TDRY-02 & -50 \\
\hline GR41A-16-74 & Formación Huaylillas & 359.182 & 7.977 .567 & 88 & Arenisca & 313 & Complejo Santa Rosa & Pozo TDY-02 & -75 \\
\hline GR41A-16-67 & Formación Huaylillas & 337.847 & 7.985 .931 & 30 & Arenisca & 315 & La Curva & Pozo TDY-01 & -51 \\
\hline GR41A-16-69 & Formación Huaylillas & 337.847 & 7.985 .931 & 30 & Arenisca & 268 & La Curva & Pozo TDY-01 & -170 \\
\hline GR41A-16-73 & Formación Huaylillas & 359.102 & 7.977 .567 & 88 & Arenisca & 267 & Complejo Santa Rosa & Pozo TDY-02 & -270 \\
\hline GR41A-16-76 & Formación Huaylillas & 359.102 & 7.977 .567 & 88 & Arenisca & 269 & Complejo Santa Rosa & Pozo TDY-02 & -190 \\
\hline GR41A-16-72 & Formación Huaylillas & 359.102 & 7.977 .567 & 88 & Arenisca & 258 & Complejo Santa Rosa & Pozo TDY-02 & -148 \\
\hline GR41A-16-68 & Formación Huaylillas & 337.847 & 7.985 .931 & 30 & Arenisca & 275 & La Curva & Pozo TDY-01 & -147 \\
\hline GR41A-16-64 & Formación Moquegua Superior & 346.914 & 7.984 .783 & 62 & Arenisca & 277 & Los Palos & Pozo TDRY-02 & -238 \\
\hline GR41A-16-65 & Formación Moquegua Superior & 346.914 & 7.984 .783 & 62 & Arenisca & 292 & Los Palos & Pozo TDRY-02 & -326 \\
\hline GR41A-16-75 & Formación Moquegua Superior & 359.102 & 7.877 .567 & 88 & Arenisca & 328 & Complejo Santa Rosa & Pozo TDY-02 & -372 \\
\hline GR41A-16-70 & Formación Moquegua Superior & 337.847 & 7.985 .931 & 30 & Arenisca & 260 & La Curva & Pozo TDY-01 & -183 \\
\hline GR41A-16-66 & Formación Moquegua Superior & 346.914 & 7.984 .783 & 62 & Arenisca & 295 & Guacano Chico & Pozo TDY-02 & -370 \\
\hline GR41A-16-71 & Formación Moquegua Superior & 337.847 & 7.985 .931 & 30 & Arenisca & 300 & La Curva & Pozo TDY-01 & -270 \\
\hline
\end{tabular}

Véase la posición estratigráfica de las muestras en las figuras 8,9 y 10. Las coordenadas se hallan en el sistema utm con datum wgs84. 
Bernet y Garver, 2005). El trabajo se fundamenta en un mapa geológico detallado (Fig. 2) el cual se complementa con la elaboración de columnas estratigráficas en sitios estratégicos. El análisis de facies sedimentarias se realizó con los criterios propuestos por Miall (1996, 2014), los que asignan códigos a las facies de acuerdo con su respectivo arreglo sedimentario interno.

El método empleado para conocer la proveniencia del material sedimentario que constituye las rocas del área es el análisis de minerales pesados. Se considera que este análisis es una herramienta útil para la definición del tránsito sedimentario y su interacción con la geodinámica (Morton y Hallsworth, 1999), así como también que provee argumentos robustos para establecer correlaciones estratigráficas en la cuenca Moquegua. Se siguieron los procedimientos sugeridos por Mange y Maurer (1992) para extraer minerales pesados y generar espectros que permitan identificar las probables rocas fuentes de los sedimentos cenozoicos. En un afán de entender la extensión lateral de las diferentes unidades estratigráficas hacia el subsuelo de Tacna y alrededores se han analizado los testigos y registros de pozos de perforación, donde a la vez se han colectado muestras para generar espectros de minerales pesados. Las concentraciones de minerales pesados fueron obtenidas después de tamizar la fracción $75-150 \mu \mathrm{m}$ y sumergirla en politungstato de sodio ("líquido pesado") a una densidad de $2,87 \mathrm{~g} / \mathrm{cm}^{3}$. La fracción resultante fue montada en slides con resina Cargille Meltmount $(1,66)$. Finalmente se contaron alrededor de 250-300 granos por muestra con un microscopio petrográfico de luz transmitida.

La edad depositacional de los sedimentos ha sido restringida mediante el uso de geocronología (U-Th)/He en apatitos y U-Pb en circones detríticos según lo propuesto por Bowring y Schmitz (2003) y Reiners et al. (2005). El helio fue extraído en un sistema de datación Alfacrono ASI (Universidad de Arizona) aplicando calor en una cámara de vacío con diodos de láser de $980 \mathrm{~nm}$, por 5 minutos a 9 Amps. $\mathrm{El}$ análisis $\mathrm{U}-\mathrm{Pb}$ por ablación láser se realizó en un ICP-MS Excimer en el Laboratorio del Servicio Nacional de Geología y Minería (Chile), también sobre circones de rocas volcanosedimentarias.

\section{Contexto geológico}

La orogenia ocurrida en los Andes Centrales y su respuesta a la sedimentación son un buen ejemplo para entender los efectos en superficie de la subducción oblicua y diferencial entre las placas de Nazca y Sudamericana (e.g., Isacks et al., 1988; Oncken et al., 2006). Según estos últimos autores, algunos de los efectos de esta interacción se reflejan en el levantamiento de cordilleras, así como también en la generación de grandes depresiones o espacios de acumulación sedimentaria. Algunas de estas cordilleras se encuentran a lo largo del margen del sur de Perú y se les conoce como cordillera de la Costa y cordillera Occidental (Bellido, 1969; Benavides, 1999) (Fig. 1C). Según Marocco et al. (1985), el borde paleogeográfico oriental de la cuenca sedimentaria Moquegua corresponde a la cordillera Occidental (sombreado verde en la Fig. 1C), mientras el borde occidental corresponde a la cordillera de la Costa (sombreado marrón claro en la Fig. 1C). Sin embargo, la cordillera de la Costa no está presente en la zona de estudio, debido a una concavidad producida en el borde costero asociada a diferencias en el proceso de subducción (Madella et al., 2018). Las rocas sedimentarias de la cuenca Moquegua se hallan en la depresión Central, también conocida como Antearco Interno (sombreado amarillo en la Fig. 1C). El basamento de la cuenca sedimentaria Moquegua está compuesto de rocas precenozoicas.

\subsection{Litología del basamento de la cuenca Moquegua}

Según la cartografía geológica provista en la figura 2, las rocas más antiguas de Tacna afloran en la cordillera Occidental y corresponden a gneises, pegmatitas y anfibolitas del Basamento Metamórfico Mal Paso (BMMP, Bellido y Narváez, 1960) o también conocido como Complejo Basal de la Costa (CBC, Wilson y García, 1962). En discordancia sobre las rocas del CBC se dispone una secuencia de aproximadamente $200 \mathrm{~m}$ de espesor, constituida por conglomerados, areniscas y lutitas negras del Grupo Ambo (Carbonífero, Wilson y García, 1962). Sobre una disconformidad que marca el techo del Grupo Ambo, se dispone una sucesión potente de aproximadamente $2.000 \mathrm{~m}$ de espesor, compuesta de andesitas basálticas de la Formación Junerata/ Chocolate (Wilson y García, 1962; Monge y Cervantes, 2000). Su edad de depositación ha sido atribuida al Jurásico Inferior por Wilson y García (1962) y su ocurrencia está relacionada con el inicio del proceso de rifting acontencido durante el Mesozoico y que originó la Cuenca sedimentaria Arequipa-Tarapacá 
(Vicente, 1981). Sobre esta secuencia de rocas volcánicas yacen calizas (mudstone a grainstone) y margas de las formaciones Pelado y Socosani (Wilson y García, 1962; Monge y Cervantes, 2000). Estas calizas conforman una secuencia de aproximadamente $500 \mathrm{~m}$ de espesor y tienen edades que varían desde el Sinemuriano al Bajociano (Acosta et al., 2011; Benites, 2017). A estas rocas carbonatadas se les ha agrupado aquí como "rocas jurásicas" (Jm-pe/so en la figura 2). Concordantemente les sobreyace una secuencia de alrededor de $1.500 \mathrm{~m}$ de espesor, conformada por el Grupo Yura y la Formación Hualhuani (Wilson y García, 1962; Vicente, 1981), la cual está compuesta por una alternancia de areniscas cuarzosas y lutitas negras asignadas al intervalo Jurásico Medio-Cretácico Inferior (Alván et al., 2018).

De modo discordante y erosivo sobreyacen rocas volcánicas y volcanosedimentarias del Grupo Toquepala, cuya edad fue definida entre el intervalo Campaniano-Paleoceno sobre la base de dataciones U-Pb por Bellón y Lefévre (1976). La cordillera de la Costa tiene escasa expresión en la zona de estudio, aunque tanto al norte como al sur del área estudiada sí se evidencia y representa unidades geomorfológicas significantes (>500 m s.n.m.) o bordes de cuenca (e.g., Arequipa, $16^{\circ} \mathrm{S}$, Alván et al., 2015). Las rocas que conforman esta cordillera en Tacna consisten en sienogranitos del Batolito de San Nicolás (Ordovícico) y granitos y granodioritas del Batolito de la Costa (unidades intrusivas Challaviento e Ilo, del Cretácico Superior a Eoceno Medio) (Narváez, 1964).

\subsection{Rocas cenozoicas en el área de Tacna}

Desde los inicios del Cenozoico una gran cantidad de sedimentos se acumularon en las cuencas de antearco Moquegua y Azapa, del sur de Perú y norte de Chile, respectivamente (Salas et al., 1966; Bellido, 1975; Marocco et al., 1985). De acuerdo con estos autores, los sedimentos acumulados reflejan ambientes fluviales, lacustres y parcialmente volcánicos (con influencia piroclástica calcoalcalina), y tienen al menos $800 \mathrm{~m}$ de espesor estratigráfico en sus depocentros más conocidos, tales como los valles de Majes y Moquegua de Perú (Bellido, 1969).

De acuerdo con Marocco et al. (1985) y Sánchez et al. (2000), las rocas sedimentarias y volcanosedimentarias están organizadas en cinco formaciones, i.e., Sotillo (Paleoceno), Moquegua Inferior (Eoceno), Moquegua Superior (Oligoceno), Huaylillas (Mioceno) y Millo (Plioceno) (Fig. 2), sobre la base de sus atributos litológicos y contactos erosivos marcados. La Formación Sotillo aflora en la localidad de Locumba (noroeste de Tacna) con aproximadamente $60 \mathrm{~m}$ de espesor y consiste en limolitas y areniscas rojizas, localmente con mucho yeso dispuesto como capas y como nódulos (Acosta et al., 2002). Según Marocco et al. (1985) y Sánchez et al. (2000), sobre la Formación Sotillo yacen las rocas de la Formación Moquegua Inferior, las cuales consisten en conglomerados y areniscas rojizas. Sus afloramientos son escasos (se restringe al suroeste de la ciudad de Moquegua) y sus espesores varían entre 20 y $60 \mathrm{~m}$. La Formación Moquegua Superior tiene espesores que varían entre 150 y $250 \mathrm{~m}$. Sobreyace a la Formación Moquegua Inferior, y yace directamente sobre las rocas de la Formación Sotillo a través de una base erosiva diacrónica. Localmente también yace en forma directa sobre el basamento de la cuenca (i.e., Grupo Yura y $\mathrm{CBC}$ ); el hiato es aun más marcado mientras más cercano esté el depósito a la cabecera de la cuenca (cordillera Occidental). Los primeros estudios sobre las facies sedimentarias de la Formación Moquegua en Tacna fueron realizados por Acosta et al. (2002), Acosta (2004) y Flores (2004), quienes indicaron que estas representan depósitos sedimentarios de ambientes canalizados y están organizadas en sets granodecrecientes (conglomerados a areniscas). Estas características permitieron diferenciar a la Formación Moquegua Superior de las adyacentes unidades sedimentarias sin dificultad. Sin embargo, la situación es distinta hacia la parte superior de esta unidad debido a que se presentan intercalaciones de estratos delgados ( $<2 \mathrm{~m}$ de espesor) de depósitos piroclásticos (Unidad MoqC1 de Decou et al., 2011), lo cual complica la definición del contacto con los piroclastos sobreyacentes de la Formación Huaylillas, y más aun cuando observamos que esta unidad suele presentar conglomerados (ver Sección 4 para mayores detalles).

La actividad volcánica más intensa del Arco Huaylillas se dio a inicios del Mioceno (Noble et al., 1985; Mamani et al., 2010), depositándose así estratos muy extensos y gruesos de ignimbritas $(<500 \mathrm{~m}$ de espesor). En la provincia de Tacna, tales depósitos fueron nombrados como Formación Huaylillas por Wilson y García (1962) y son 
conocidos también como "Superficie Huaylillas" por constituir una estructura geomorfológica muy amplia que se extiende hasta el norte de Chile ("Superficie Huaylas", Wörner et al., 2000), con las formaciones Oxaya y El Diablo. De acuerdo con Evenstar et al. (2017), esta geoforma es una "superficie abandonada" y su ocurrencia se debe a la instalación de climas hiperáridos, donde la erosión es efectivamente nula, mientras la incisión de valles es muy local y efímera. Naturalmente, en su parte oriental proximal (Altiplano), la Formación Huaylillas es más piroclástica (Wörner et al., 2000; Mamani et al., 2010), mientras que en su parte distal (e.g., depresión Central de las provincias de Moquegua y Tacna) se reporta mayor cantidad de intercalaciones de conglomerados y areniscas (Alván et al., 2017b). Esta complejidad hace que el límite con la subyacente Formación Moquegua Superior sea parcialmente arbitrario (ver Sección 4 para más información). Sobreyaciendo a la Formación Huaylillas se disponen las unidades litológicas de la Formación Millo (ca. $45 \mathrm{~m}$ de espesor, Sánchez et al., 2000) a través de una base erosiva diacrónica (Sempere et al., 2004). Estos últimos autores y Flores (2004) describieron sucesiones grano y estratodecrecientes de conglomerados soportados por una matriz de areniscas, cuyos clastos corresponden a andesitas, riolitas y dacitas de afinidad alcalina a calcoalcalina (Mamani et al., 2010). Su arquitectura estratigráfica fue atribuida a numerosas etapas de avulsión de canales fluviales, sin embargo, su ocurrencia en Tacna es muy restringida. Más hacia el este, yacen andesitas y riolitas y pequeños volúmenes de ignimbritas asignadas a la Formación Barroso (Plioceno, Mamani et al., 2010; Acosta et al., 2011), lo cual es una consecuencia de la actividad magmática del Arco Barroso (Mamani et al., 2012).

Los depósitos sedimentarios de mayor espesor y extensión lateral son aquellos incluidos en las formaciones Moquegua Superior y Huaylillas; por lo tanto, constituyen las unidades de mayor interés de este estudio. Verticalmente, ambas unidades pueden presentar espesores mayores de $600 \mathrm{~m}$ y lateralmente pueden extenderse hasta por $200 \mathrm{~km}$ a lo largo de la depresión Central. Hacia el oeste, estos depósitos pueden alcanzar unos $50 \mathrm{~km}$ hasta la línea de la costa con sus correspondientes variaciones de facies (Marocco et al., 1985), y es muy posible que se extiendan aguas afuera de la costa de Tacna, tal como lo han planteado Alván et al. (2017a).

\section{Desafios para el establecimiento de un esquema cronoestratigráfico para el Cenozoico del área de Tacna}

Como se ha indicado líneas arriba, uno de los mayores problemas surge en la definición de los límites estratigráficos y de las edades depositacionales de las unidades litoestratigráficas en estudio, dada la ausencia de fósiles guías y dataciones en las rocas sedimentarias. Esta dificultad se aborda mediante el reconocimiento y análisis de las facies sedimentarias cenozoicas en asociación con métodos basados en el análisis de minerales pesados, y con la realización de dataciones radiométricas en sedimentos volcanoclásticos a fin de estimar el inicio de la depositación sedimentaria.

Marocco et al. (1985) consideraron que la Formación Sotillo es la unidad más antigua del relleno sedimentario de la cuenca Moquegua y la asignaron al Paleoceno. La coloración roja de estos estratos es muy característica y contrasta con las unidades litológicas sobreyacentes, lo que facilita su reconocimiento de campo. Este criterio fue empleado en la provincia de Arequipa por Sempere et al. (2004) y Decou et al. (2011) para discriminar, en su depocentro (Aplao y Corire), las rocas pertenecientes a la Formación Sotillo de las demás unidades sobreyacentes. En el área de estudio tales estratos solo afloran en el cerro Yarahuay (15 km al noreste de Tomasiri, Fig. 2), situación que dificulta el reconocimiento de sus relaciones estratigráficas.

Otro desafio surge al tratar de definir el límite entre las formaciones Moquegua Superior y Huaylillas. Si bien esta última es fácilmente distinguible por ser una unidad piroclástica producto del volcanismo Huaylillas (24-10 Ma, Mamani et al., 2010), en la zona de estudio contiene en su base numerosas interdigitaciones con estratos conglomerádicos (Tosdal et al., 1981), lo cual hace que la ubicación de tal límite sea arbitraria. Finalmente, el problema con las rocas de la Formación Millo es aun más complejo debido a que no se cuenta con afloramientos adecuados para entender mejor su génesis sedimentaria. A la fecha, se conoce que esta unidad solo aflora en el cerro Magollo (6 $\mathrm{km}$ al suroeste de la ciudad de Tacna, Fig. 2), mientras su extensión en el subsuelo es desconocida. Estos desafíos ameritan el empleo de métodos analíticos que permitan caracterizar mineralógica y geocronológicamente los detritos cenozoicos del área de Tacna. 


\section{Resultados}

\subsection{Análisis de facies sedimentarias}

Sobre las formaciones Sotillo y Moquegua Inferior yacen sucesivamente las formaciones Moquegua Superior, Huaylillas y finalmente Millo (Fig. 2), y son estas tres últimas las consideradas en este estudio. Cada una de estas unidades está dividida por límites estratigráficos erosivos y diacrónicos (Sempere et $a l ., 2014)$. Esta afirmación es extensible también para la parte más occidental de la zona de estudio, donde se hallan los registros estratigráficos de los pozos de perforación obtenidos en La Yarada (ver Sección 6.3 para mayor información). En las rocas de las formaciones Moquegua Superior, Huaylillas y Millo se han identificado nueve facies sedimentarias, las cuales fueron adaptadas de acuerdo con los códigos propuestos por Miall (1996) (Tabla 2). Tales facies son (i) facies Gmn (gravas matriz-soportadas, Fig. 3A), (ii) facies Gcn (gravas clastosoportadas, Fig. 3B y C), (iii) facies $S x$ (areniscas con estratificación cruzada, Fig. 3D y E), (iv) facies $S h$ (areniscas con laminación horizontal o paralela, Fig. 3B), (v) facies $\mathrm{Sm}$ (arenisca maciza, sin estructuras internas, Fig. 3F), (vi) facies $F l$ (limolitas y lutitas con laminaciones paralelas u horizontales) y (vii) facies $F m$ (limolitas y lutitas macizas, sin estructuras internas). Además, se reconocieron facies piroclásticas con una marcada influencia detrítica. Estas pueden ser clasificadas como (viii) facies $T b 1$ (tobas/cenizas macizas) y (ix) facies $T b 2$ (tobas/cenizas estratificadas). Según lo reportado por Acosta et al. (2002), el común denominador de estas sedimentitas es su disposición en secuencias granodecrecientes, iniciando en conglomerados matriz-soportados hasta areniscas con laminaciones oblicuas y paralelas (facies $G m m, S x$ y $S h$ ).

La definición de estas facies sedimentarias ayudó a refinar el cartografiado geológico, donde se logró constatar que gran parte de los depósitos que fueron asignados por Sánchez et al. (2000) a la Formación Millo (e.g., cerros Hospicio, Espíritus, Chatudal, Los Cóndores, Los Churcos, ente otros), en realidad corresponden a la Formación Huaylillas. En ese contexto, nuestras observaciones son similares a las propuestas por Jaén y Ortiz (1963) y Acosta et al. (2011), quienes afirman que todos los afloramientos de rocas sedimentarias del área de Tacna forman parte de la Formación Huaylillas. Sin embargo, este estudio discrepa parcialmente debido a que también afloran rocas asignables a la Formación Moquegua Superior debajo de la Formación Huaylillas y en contacto irregular (erosivo), como se plantea en el mapa geológico de la figura 2.

\section{TABLA 2. IDENTIFICACIÓN DE NUEVE FACIES SEDIMENTARIAS EN LAS ROCAS CENOZOICAS DE TACNA,} DE ACUERDO CON MIALL (1996).

\begin{tabular}{|c|c|c|}
\hline Facies & Descripción & Espesor (m) \\
\hline Gcn & $\begin{array}{l}\text { Gravas con clastos soportados entre ellos, generalmente estratificados, y en gradación normal. } \\
\text { Los clastos pueden tener entre } 10 \text { y } 5 \mathrm{~cm} \text {; también entre } 0,5 \text { y } 2 \mathrm{~cm} \text {. }\end{array}$ & $1-2$ \\
\hline Gmn & $\begin{array}{l}\text { Gravas con clastos soportados por matriz de arenisca, generalmente estratificados y en } \\
\text { gradación normal. Los clastos pueden tener entre } 10 \text { y } 5 \mathrm{~cm} \text {. }\end{array}$ & $<5$ \\
\hline$S x$ & $\begin{array}{l}\text { Areniscas, de grano grueso y/o medio, generalmente de ordenamiento pobre, con laminaciones } \\
\text { oblicuas de alto y bajo ángulo, generalmente con base cóncava o semiplana. }\end{array}$ & $<1$ \\
\hline Sh & $\begin{array}{l}\text { Areniscas de grano grueso y/o medio con laminaciones paralelas y/o estratificación horizontal. } \\
\text { Usualmente estratos tabulares. }\end{array}$ & $0,5-0,7$ \\
\hline$S m$ & $\begin{array}{l}\text { Areniscas macizas de grano medio y grueso, bien a moderadamente ordenadas, sin estructuras } \\
\text { sedimentarias internas. Usualmente estratos tabulares. }\end{array}$ & $<1$ \\
\hline $\boldsymbol{F l}$ & $\begin{array}{l}\text { Limolitas y lutitas con laminaciones paralelas y/o horizontales. Algunas veces presenta } \\
\text { deformaciones tipo laminaciones convolutas. }\end{array}$ & 0,3 \\
\hline Fm & $\begin{array}{l}\text { Limolitas y lutitas macizas, usualmente con alguna bioturbación. Puede presentar } \\
\text { comúnmente grietas de desecación. }\end{array}$ & 0,5 \\
\hline Tb1 & Lapilli-tobas o lapilli-cenizas macizas, grises rosáceas, usualmente con ligeras laminaciones. & $>10$ \\
\hline$T b 2$ & $\begin{array}{l}\text { Tobas, grises claras, con clastos aislados generalmente en la base de la sucesión, usualmente } \\
\text { estratificado. }\end{array}$ & $1-2$ \\
\hline
\end{tabular}



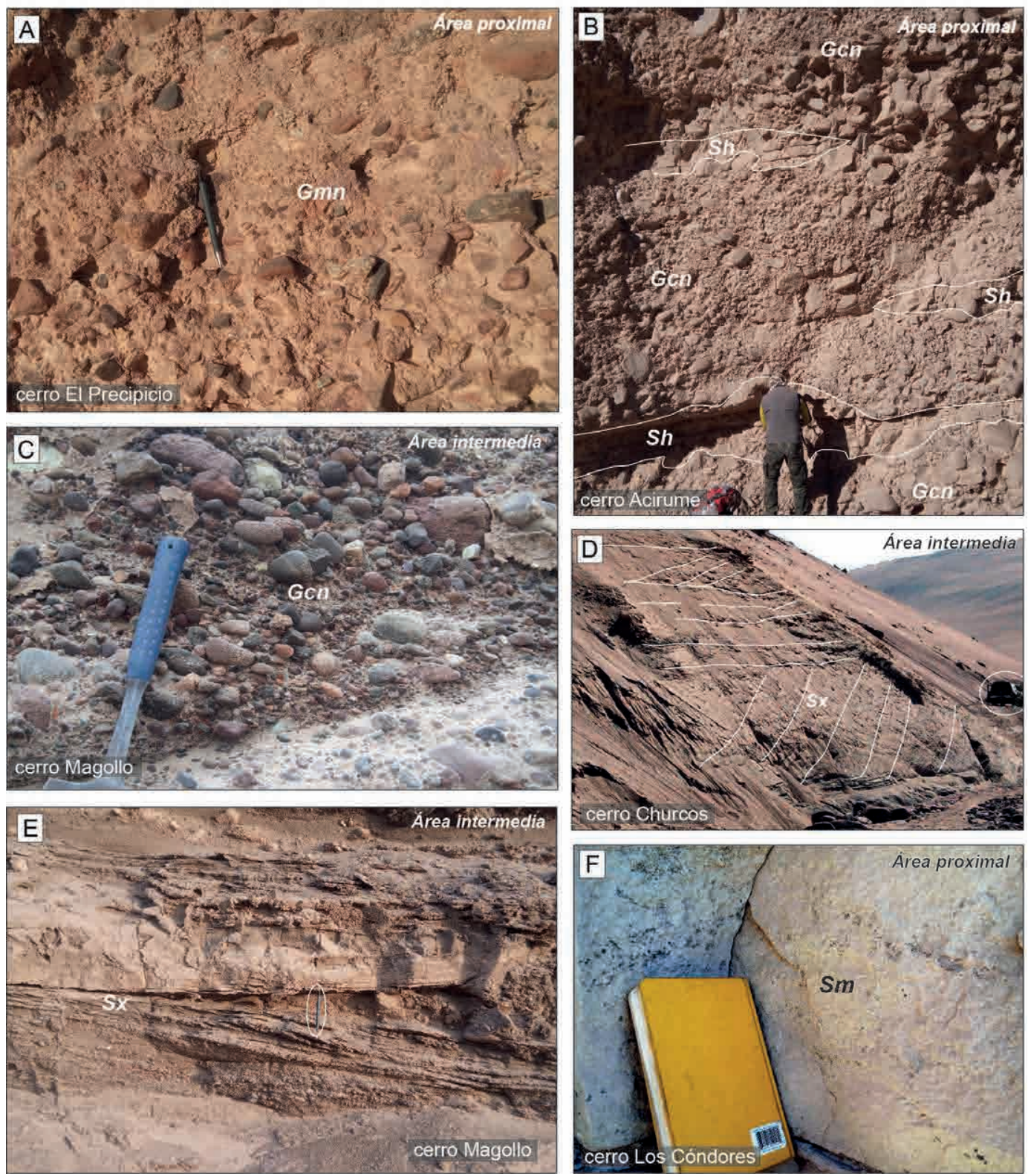

FIG. 3. Principales facies sedimentarias identificadas en las rocas cenozoicas de Tacna. A. Facies Gmn, conglomerados soportados por matriz (cerro El Precipicio). B. Facies Gcn (conglomerados soportados por clastos) en asociación con facies $S h$, areniscas laminadas (cerro Acirume). C. facies Gcn, conglomerados con clastos en posición imbricada hacia el suroeste (cerro Magollo). D. Facies $S x$, areniscas con laminaciones cruzadas (cerro Churcos). E. Facies $S x$, areniscas con laminaciones cruzadas (cerro Magollo), y con ocasionales conglomerados (ver martillo como escala en círculo blanco). F. Facies Sm, areniscas macizas (cerro Los Cóndores).

Una vez definidas las facies sedimentarias, estas se agruparon en cinco elementos arquitecturales (Tabla 3) que corresponden a (i) $\mathrm{CH}$ (canales fluviales), (ii) $D A$ (acreción río abajo), (iii) $S B$ (estratos y barras arenosas), (iv) FF (depósitos tipo floodplain o de rebalse), y finalmente (v) $P Y$ (depósitos piroclásticos). Las columnas estratigráficas de afloramientos y los registros litológicos de los pozos de perforación han 
TABLA 3. DEFINICIÓN DE CINCO ELEMENTOS ARQUITECTURALES EN LOS DEPÓSITOS CENOZOICOS DE LOS ALREDEDORES DE LA CIUDAD DE TACNA, DE ACUERDO CON MIALL (1996).

\begin{tabular}{|c|c|c|c|c|}
\hline Código & $\begin{array}{c}\text { Elemento } \\
\text { arquitectural }\end{array}$ & Facies & Ocurrencia & Geometría depositacional \\
\hline $\mathrm{CH}$ & Canal fluvial & $\begin{array}{l}\text { Gcn, } \\
G m n, S x\end{array}$ & $\begin{array}{l}\text { Mayoría de columnas } \\
\text { estratigráficas, excepto } \\
\text { en Churcos. }\end{array}$ & $\begin{array}{l}\text { Canales fluviales generalmente confinados, muy } \\
\text { anchos a anchos }(<1 \mathrm{~km}) \text {. Si la matriz es pobre, puede } \\
\text { corresponder a abanicos aluviales. }\end{array}$ \\
\hline$D A$ & $\begin{array}{l}\text { Acreción río abajo } \\
\text { (progradante) }\end{array}$ & $S x, S h$ & $\begin{array}{l}\text { Yarahuay, Churcos, } \\
\text { Chuschuco, Los } \\
\text { Cóndores. }\end{array}$ & $\begin{array}{l}\text { Lentes o cuerpos linguoidales de areniscas, } \\
\text { generalmente canalizados y con base erosiva, los } \\
\text { cuales representan progradación sedimentaria en } \\
\text { dirección río abajo. }\end{array}$ \\
\hline$S B$ & $\begin{array}{l}\text { Estratos/barras } \\
\text { arenosas }\end{array}$ & $\begin{array}{l}S x, S m, \\
S h\end{array}$ & $\begin{array}{l}\text { Chuschuco El Perdido, } \\
\text { Churcos. }\end{array}$ & $\begin{array}{l}\text { Lentes o cuerpos sedimentarios de menor escala que se } \\
\text { encuentran como relleno de canal o interbarras; barras } \\
\text { de menor escala compuestas de areniscas. }\end{array}$ \\
\hline$F F$ & Depósitos de rebalse & $F m, F l$ & $\begin{array}{l}\text { Mayoría de testigos de } \\
\text { pozos de perforación, } \\
\text { Churcos. }\end{array}$ & $\begin{array}{l}\text { Pueden ser depósitos extensos o lenticulares. Zonas } \\
\text { semiplanas o de baja pendiente, donde existen } \\
\text { depresiones. Acumulación de sedimentos por gravedad } \\
\text { y poca energía fluvial. }\end{array}$ \\
\hline$P Y$ & $\begin{array}{l}\text { Depósitos } \\
\text { piroclásticos }\end{array}$ & $T b 1, T b 2$ & $\begin{array}{l}\text { Mayoría de testigos de } \\
\text { pozos de perforación y } \\
\text { afloramientos. }\end{array}$ & $\begin{array}{l}\text { Pueden ser depósitos extensos y tabulares. Zonas } \\
\text { semiplanas o de baja pendiente y que rellenan } \\
\text { paleodepresiones. }\end{array}$ \\
\hline
\end{tabular}

sido agrupados según su proximidad al borde oriental de la cuenca sedimentaria (cordillera Occidental) (ver líneas rojas en la figura 2). Tales afloramientos corresponden a los observados en los cerros Acirume (Fig. 4A), Chuschuco (Fig. 4B), El Perdido (Fig. 4C) y Los Cóndores (Fig. 4D) y representan el área proximal, adyacente al borde oriental de la cuenca. Los cerros Yarahuay (Fig. 5A), Magollo (Fig. 5C) y Churcos (Fig. 5E) representan el área media. Los registros estratigráficos de los pozos PEL-01 (Fig. 5B) y TD-V1 (Fig. 5D) también forman parte del área media. Finalmente, el área distal, próxima a la línea de costa, agrupa los registros estratigráficos que se hallan en la parte más occidental, y está representada por los testigos de los pozos de perforación TDY-01 (Fig. 6A), TDRY-02 (Fig. 6B) y TDY-2 (Fig. 6C). La propuesta de estas tres áreas depositacionales se apoya en la notoria diferencia lateral de las facies.

\subsubsection{Facies sedimentarias en las rocas de la Formación Moquegua Superior, Oligoceno}

El área proximal de la cuenca Moquegua de Tacna (sección A-A' de la Fig. 2) es aquella que se localiza más cercana a la cordillera Occidental (Fig. 4) y comprende depósitos en que predominan las facies Gmn y Gcn (Fig. 3A y B). En menor proporción hay areniscas de las facies $S h$ y $S x$, las cuales se presentan a manera de cuerpos lenticulares entre los conglomerados. Verticalmente, es muy común observar amalgamación de estas facies (véase las facies conglomerádicas en la figura 4), y generalmente tienen bases irregulares (erosivas). Hacia la parte superior de esta unidad son habituales las intercalaciones de conglomerados de facies Gmn con algunos estratos de tobas retrabajadas de la facies $T b 2$ (e.g., Fig. 4D). Los clastos en los conglomerados de las facies Gmn y Gcn son subangulosos y subredondeados, y pueden tener diámetros muy variables $(10-40 \mathrm{~cm})$. Estos se componen predominantemente de andesita, diorita, granodiorita, y en menor proporción arenisca cuarzosa (Bustamante, 2017). Esta asociación de facies se extiende por más de $4 \mathrm{~km}$ de longitud, desde el borde y hacia el centro de la cuenca, y lateralmente a lo largo de gran parte de la Depresión Central del sur de Perú y del norte de Chile (Fig. 1). Se ilustra un ejemplo de esta asociación en la parte inferior de las columnas estratigráficas de los cerros Acirume (Fig. 4A) y Chuschuco (Fig. 4B). De acuerdo con la clasificación de depósitos fluviales de Nemec y Steel (1984), estas facies pueden ser consideradas también como alternancias de depósitos tipo debris flow, grain flow y sheet flood. 


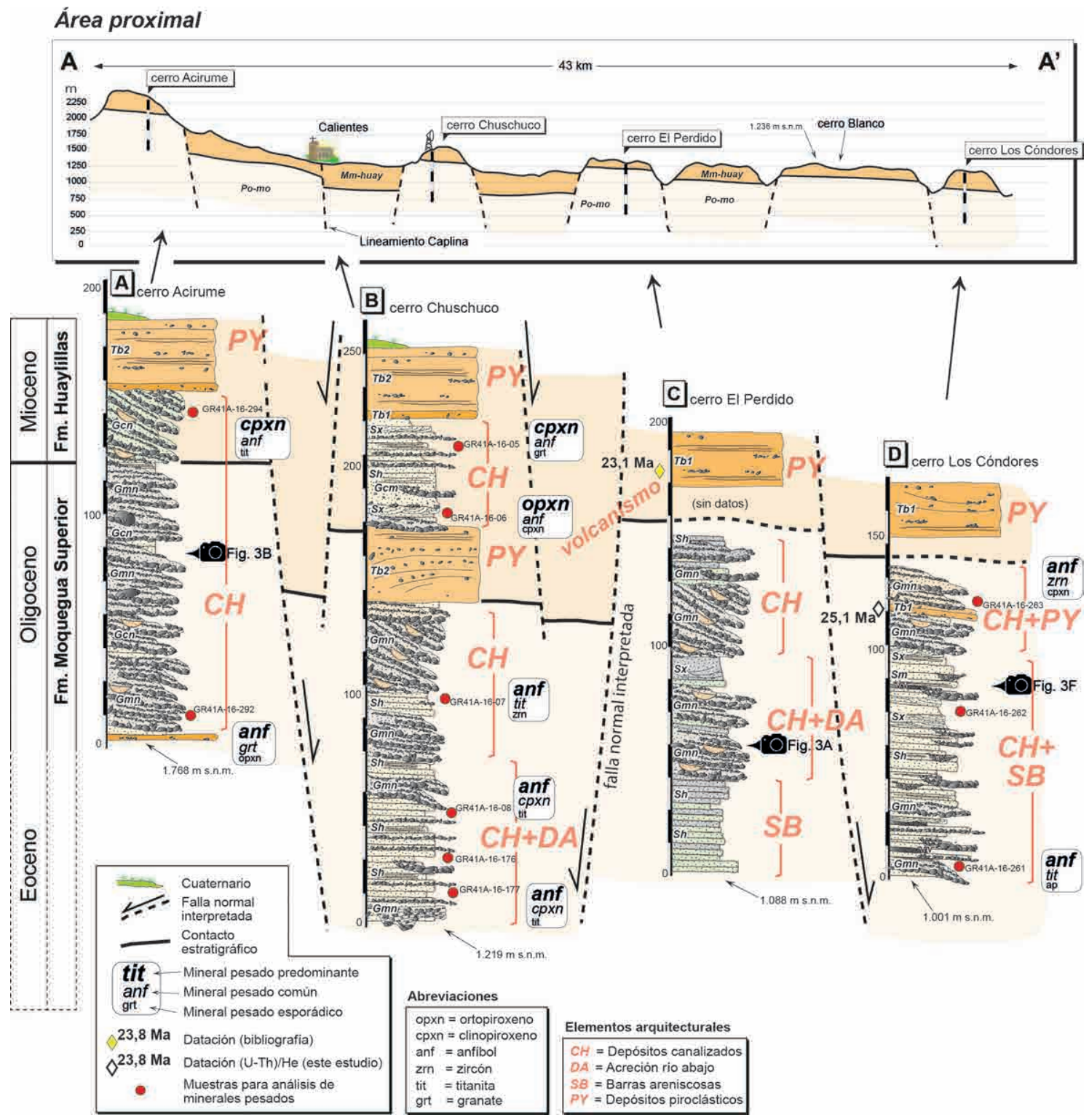

FIG. 4. Diagrama esquemático de la organización estratigráfica del Área proximal. Las unidades litoestratigráficas mostradas en este corte corresponden a las formaciones Moquegua y Huaylillas. A. Columna estratigráfica del cerro Acirume (inicio en WGS84 UTM 378.767/8.035.327/2.083 m s.n.m.). B. Columna estratigráfica del cerro Chuschuco (WGS84 UTM 382.944/8.020.316/1.324 m s.n.m.). C. Columna estratigráfica del cerro El Perdido (WGS84 UTM 387.936/8.009.596/1.130 m s.n.m.). D. Columna estratigráfica del cerro Los Cóndores (WGS84 UTM 390.971/7.997.669/992 m s.n.m.). Los círculos rojos con codificación representan las muestras colectadas (ver Sección 5.2 para más información). Las dataciones previas provienen de Bellón y Lefevre (1976), Vatin-Perignon et al. (1996) y Quang et al. (2005). Las líneas punteadas negras representan fallas normales interpretadas de alto ángulo. Esta figura hace referencia a imágenes de facies sedimentarias mostradas en la figura 3 (íconos de cámara fotográfica).

En el área media de la cuenca Moquegua en Tacna (sección B-B' de la Fig. 2) también se observan conglomerados de la facies Gcn, aunque en menor proporción, que dan paso a una mayor presencia de areniscas de las facies $S h$ y $S m$, a manera de interdigitaciones estratigráficas (e.g., Fig. 5D y E). 


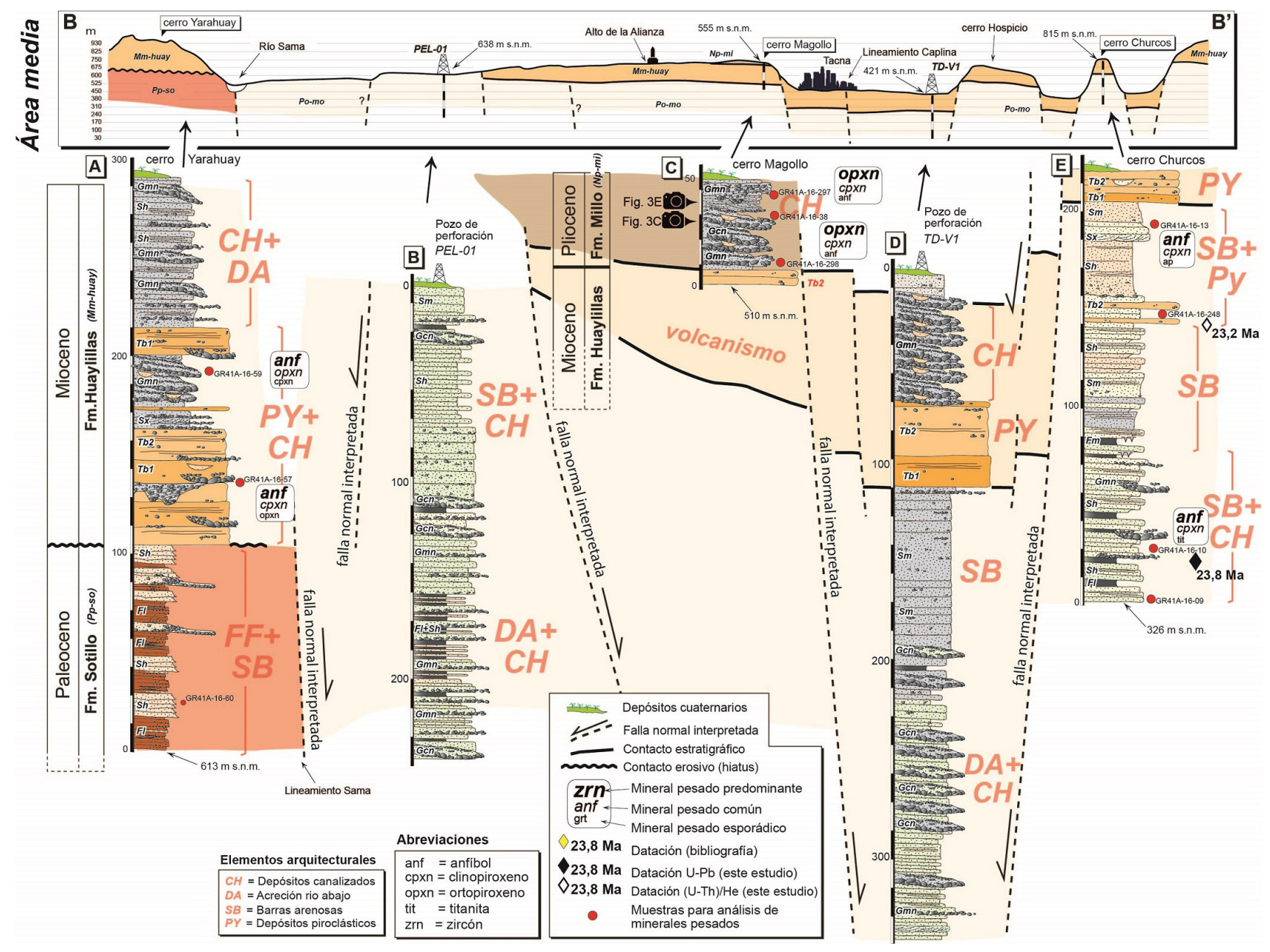
(WGS84 UTM 350.606/8.022.488/638 m s.n.m.). C. Afloramientos del cerro Magollo. D. Pozo TD-V1 (WGS84 UTM 368.888/8.000.306/421 m s.n.m.). E. Columna estratigráfica del cerro Churcos (WGS84 UTM 374.630/7.992.373/550 m s.n.m.). Los círculos rojos (codificados) representan muestras para análisis de minerales pesados. Las líneas punteadas negras representan fallas normales interpretadas de alto ángulo. Esta figura hace referencia a imágenes de facies sedimentarias mostradas en la figura 3 (íconos de cámara fotográfica). 


\section{Área distal}

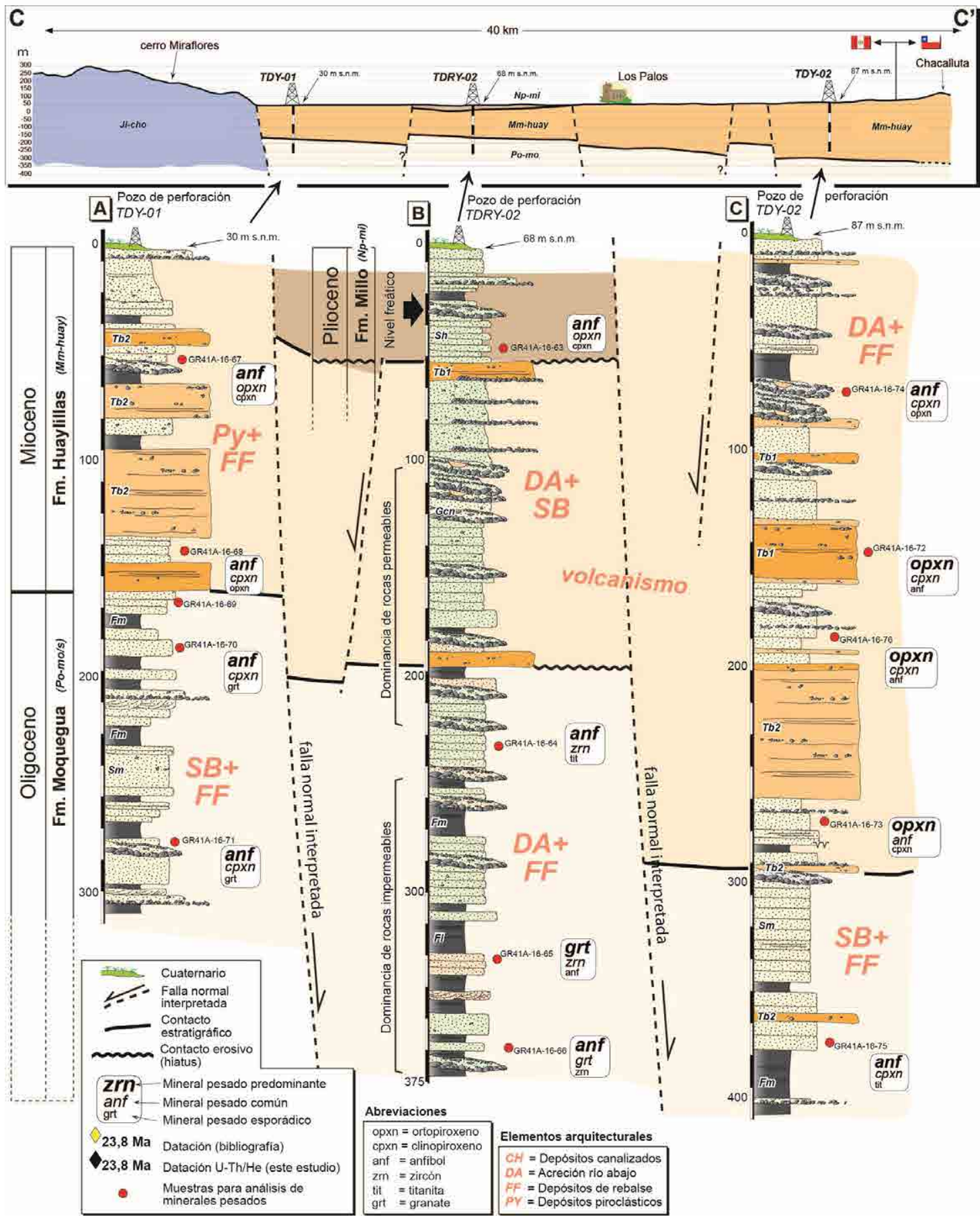

FIG. 6. Diagrama esquemático de la organización estratigráfica de los depósitos cenozoicos del subsuelo de Tacna (Área distal). Para la elaboración de este esquema se representó la estratigrafía de los testigos de pozos de perforación que fueron realizados en La Yarada por el Proyecto Especial Tacna en la década del 2000. A. Pozo TDY-01 (WGS84 UTM 337.847/7.985.931/30 m s.n.m.). B. Pozo TDRY-02 (WGS84 UTM 346.914/7.984.783/68 m s.n.m.). C. TDY-02 (WGS84 UTM 359.102/7.977.567/87 m s.n.m.). Para mayores detalles véase también Zenteno et al. (2003) y Salinas y Chambilla (2005, 2006). Las líneas punteadas negras representan fallas normales interpretadas de alto ángulo. Esta figura hace referencia a imágenes de facies sedimentarias en la figura 3 (íconos de cámara fotográfica). 
También se presenta la facies $S x$ en areniscas, las que son comunes en estratos de espesores de $40-50 \mathrm{~cm}$ y excepcionales en aquellos de hasta $3 \mathrm{~m}$. Todas estas areniscas se disponen en cuerpos tabulares y a veces parcialmente canalizados, mientras los conglomerados solo en forma canalizada y lenticular. Las areniscas pueden extenderse bajo estas facies y geometría distalmente hacia el oeste por más de $10 \mathrm{~km}$, mientras los conglomerados tienen corta extensión $(<1 \mathrm{~km})$ y conforman cuerpos lenticulares (interbarras) comúnmente con bases erosivas. Esta organización litológica también se observa parcialmente en los registros de los pozos de perforación (Fig. 5B y D), y es muy recurrente a lo largo de los afloramientos del área media de la cuenca Moquegua en Tacna. Una característica adicional de los depósitos en el área media es la presencia de algunos niveles de sedimentos de grano fino, i.e., facies $\mathrm{Fl}$ (capas grises oscuras en la Fig. 5B, D y E); sin embargo, su ocurrencia es limitada. Los clastos de los conglomerados del área distal tienen la misma composición litológica que los del área proximal, aunque sus dimensiones son menores $(2-10 \mathrm{~cm})$ y sus formas son subredondeadas.

Finalmente, en el área distal de la cuenca Moquegua en Tacna (sección C-C' de la Fig. 2), es decir, hacia el lado suroeste, se tiene llanuras contiguas a la línea de costa sin proximidad a zonas con afloramientos de rocas cenozoicas o del basamento. Sin embargo, se cuenta con registros litológicos de pozos de perforación realizados por el Proyecto Especial Tacna (PET, 2007; Salinas y Chambilla, 2005, 2006), los cuales en este estudio permiten su representación en columnas estratigráficas (Fig. 6). En tales registros se observa que los depósitos atribuidos a la Formación Moquegua Superior tienen mayor presencia de areniscas y sedimentos de granulometría aun más fina, i.e., limolitas y lutitas y corresponden a las facies $S m, S h, F l$ y $F m$.

Esporádicamente se observa la ocurrencia de estratos de conglomerados de escaso espesor $(<40 \mathrm{~cm})$ con clastos subredondeados, atribuibles a la facies Gmn. En esta área, los clastos que componen la mayoría de los depósitos conglomerádicos también están formados de arenisca cuarzosa, granodiorita, andesita y diorita, y no sobrepasan los $7 \mathrm{~cm}$ de diámetro (cf. Bustamante, 2017). La Formación Moquegua Superior, en sus tres áreas depositacionales (i.e., proximal, media y distal) incluyen en su parte superior algunas capas piroclásticas de espesores que varían de 1 a $2 \mathrm{~m}$, las cuales están compuestas de tobas de cristales atribuibles a las facies $T b 2$. Es característico que las capas de piroclastos sean más recurrentes hacia la parte superior de esta formación, lo que hace que el paso a la Formación Huaylillas sea transicional (e.g., Figs. 4D, 5E y 6C). Uno de los últimos estratos piroclásticos contiene niveles de arenisca, el cual ha sido datado en $23,8 \mathrm{Ma}$ (U-Pb en circones detríticos, muestra GR41A-16-10, Fig. 12 y Tabla 4). Otras edades presentadas en este estudio arrojan 25,1 Ma (muestra GR41A-16-263, cerro Los Cóndores) y 23,2 Ma (muestra GR41A-16-248, cerro Churcos), ambas edades (U-Th)/He en circones detríticos de niveles de arenisca de la parte superior de la Formacion Moquegua Superior. Se considera estos datos como las edades depositacionales más jóvenes de la Formación Moquegua Superior

TABLA 4. DATACIONES RADIOMÉTRICAS REALIZADAS PARA ESTE ESTUDIO.

\begin{tabular}{llccccccc}
\hline \multicolumn{1}{c}{ Muestra } & \multicolumn{1}{c}{ Unidad } & Material & Litología & Método & $\begin{array}{c}\text { Edad } \\
\text { (Ma) }\end{array}$ & Long. & Lat. & Ubicación \\
\hline GR41A-16-263 & $\begin{array}{l}\text { Formación Moquegua } \\
\text { Superior }\end{array}$ & circón & arenisca & (U-Th)/He & 25,1 & 391.077 & 7.997 .522 & Cerro Los Cóndores \\
GR41A-16-248 & $\begin{array}{l}\text { Formación Moquegua } \\
\text { Superior }\end{array}$ & circón & arenisca & (U-Th)/He & 23,2 & 385.783 & 7.994 .155 & Cerro Churcos \\
GR41A-16-10 & $\begin{array}{l}\text { Formación Moquegua } \\
\text { Superior }\end{array}$ & circón & arenisca & U-Pb & 23,8 & 371.381 & 7.990 .112 & Cerro Churcos \\
GR41A-16-290 & $\begin{array}{l}\text { Unidad Intrusiva } \\
\text { Challaviento }\end{array}$ & apatito & granodiorita & (U-Th)/He & 35,3 & 381.437 & 8.051 .540 & Guacano Chico \\
GR41A-16-50 & $\begin{array}{l}\text { Complejo Basal de la } \\
\text { Costa }\end{array}$ & circón & gneis & (U-Th)/He & 42,7 & 387.393 & 8.051 .488 Guacano Chico \\
\hline
\end{tabular}

Véase la distribución espacial de estas muestras en la figura 2 (rombos) y su posición estratigráfica en las figuras 4 y 5 . Las coordenadas se hallan en el sistema utm con datum wgs 84 . 
(ver Sección 6.1 para mayores detalles). Sin embargo, localmente es posible observar que el tope de la Formación Moquegua Superior puede ser erosivo y diacrónico (Sempere et al., 2004, 2014).

Interpretación. Según lo sugerido por Miall (1996, 2014), y consistente con lo documentado por Acosta et al. (2002), las asociaciones de facies observadas en las rocas de la Formación Moquegua Superior reflejan el establecimiento de los elementos arquitecturales $\mathrm{CH}$ (canales) preferentemente en el área proximal, mientras que los elementos DA (acreción río abajo) y SB (barras areniscosas) son más recurrentes en el área media, donde hay una menor proporción de depósitos con los elementos $\mathrm{CH}$ (Fig. 7A). En su parte más distal, se aprecia la dominancia de elementos arquitecturales SB, DA y FF (depósitos de rebalse), los cuales muy esporádicamente están asociados con algunas de las facies conglomerádicas Gmn (Fig. 7A). La distribución horizontal de estos elementos refleja claramente una arquitectura estratigráfica fluvial del tipo trenzado (braided), en donde la acreción y avulsión son típicamente río abajo (downward), con facies gruesas en la parte proximal (cerca de la cordillera Occidental) y facies finas hacia la parte distal (próximo a la actual línea de costa). Estos ambientes se caracterizan, además, por la presencia de canales fluviales multilaterales, los que son una respuesta a su naturaleza acrecionaria progradante. Los canales de esta unidad son también móviles verticalmente y se interpreta que volumétricamente excedieron el espacio de acomodación en su recorrido. Además, ocasionalmente existieron llanuras de inundación, aunque en las zonas más distales de esta parte del antearco. Se resalta igualmente la presencia de cuerpos sedimentarios de origen eólico (Fig. 3D), lo cual permite sugerir una intermitencia de periodos áridos e hiperáridos. La aparición de numerosos estratos y niveles con tobas de las facies $\mathrm{Tb} 2$ en la parte superior de la Formación Moquegua permite sugerir la finalización de la depositación fluvial trenzada y marcaría la antesala de la actividad volcánica del Arco Huaylillas.

\subsubsection{Facies sedimentarias en las rocas de la Formación Huaylillas, Mioceno}

Estas rocas yacen sobre la Formación Moquegua Superior, comúnmente sobre una base erosiva. Se observa que en la mayoría de afloramientos y columnas estratigráficas presentadas en este estudio hay numerosas intercalaciones de depósitos con rocas piroclásticas, las cuales son atribuidas a la actividad del Arco Volcánico Huaylillas (24-10 Ma, Mamani et al., 2010, 2012). Estos depósitos son clasificados en este estudio como tobas de lapilli (macizas, $T b 1$ ), y como tobas de ceniza (estratificadas, $\mathrm{Tb} 2$ ). Al igual que Marocco y Noblet (1990), este estudio considera que tal actividad ocurrió de forma coetánea a la sedimentación (fluvial). En tal contexto, la Formación Huaylillas puede tener tantas intercalaciones de rocas volcánicas piroclásticas como el ambiente sedimentario predominante y la paleogeografía se lo permita (por ejemplo, depresiones locales versus altos paleogeográficos). Esta afirmación se refleja en su común asociación (intercalaciones) con depósitos sedimentarios canalizados compuestos de conglomerados (que contienen clastos de andesitas y dacitas) y areniscas a manera de interbarras atribuibles a las facies $G c m$ y $S h$ y $S x$, respectivamente. Se puede concluir que las facies $T b 1$ y $T b 2$ están asociadas al elemento arquitectural $\mathrm{CH}$, y también a los elementos $D A$ y/o $S B$. Se observa además que a lo largo de cuenca Moquegua en Tacna, existen diferencias muy notorias en los espesores estratigráficos de estas unidades piroclásticas observables tanto en los afloramientos como en los testigos de pozos de perforación (Figs. 4, 5 y 6).

Similar a la organización sedimentológica de los depósitos de la Formación Moquegua Superior, la ocurrencia de facies conglomerádicas (i.e., Gcn y $G m n$ ) se concentra en el área proximal de la cuenca Moquegua en Tacna, mientras las facies areniscosas (i.e., $S x, S h$ y $S m$ ) y finas (i.e., $F l$ y $F m$ ) aumentan hacia la parte distal. En tal contexto, los elementos arquitecturales $\mathrm{CH}$ se hacen menos recurrentes hacia las áreas media y distal, y dan paso a la aparición de los elementos $D A$ y $S B$, y muchas veces al elemento $F F$, conforme la sedimentación sea aun más distal. Por otro lado, la presencia de las facies piroclásticas es indistinta a la proximidad de la cordillera Occidental, es decir, pueden ocurrir espesores mayores en el área proximal o distal de la cuenca, y con más énfasis conforme se esté más cerca de la provincia de Arica, norte de Chile. Las rocas de la Formación Huaylillas en las planicies de La Yarada y los alrededores de Los Palos pueden ser encontradas a partir de $50 \mathrm{~m}$ de profundidad, y pueden alcanzar espesores de hasta $300 \mathrm{~m}$, con intercalaciones de depósitos clásticos (Fig. 6C). La diferencia de espesores de esta unidad puede tener un significado paleogeográfico o incluso sintectónico. 

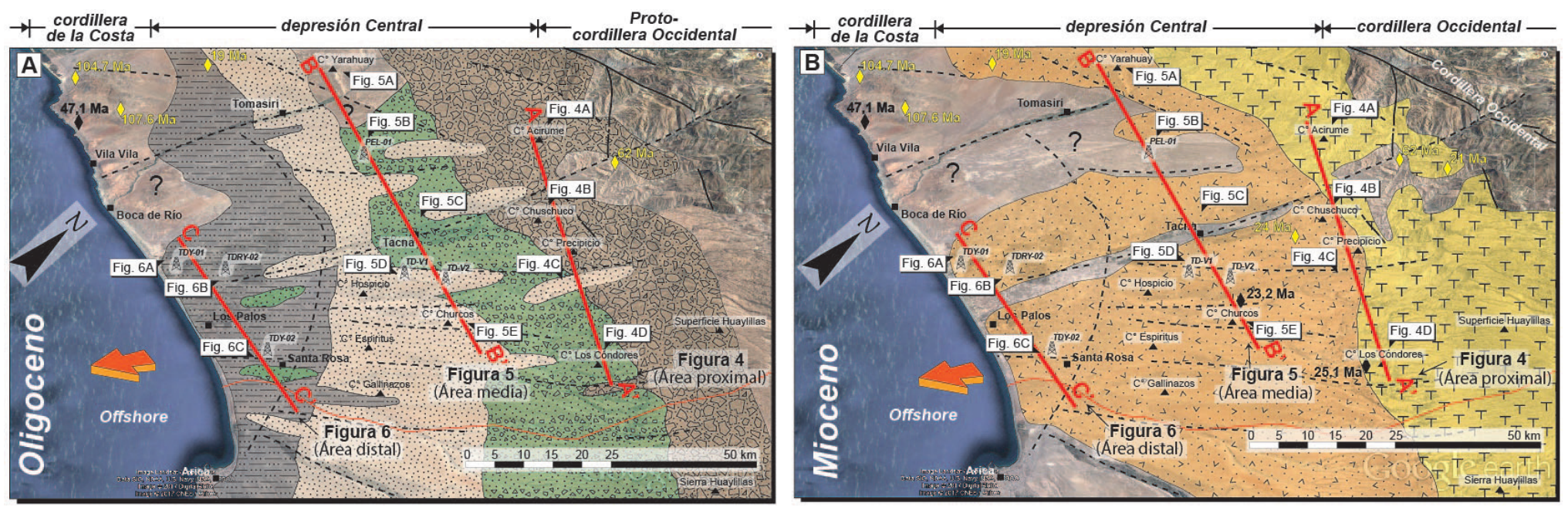

\begin{tabular}{|c|c|}
\hline \multicolumn{2}{|c|}{ Elementos arquitecturales } \\
\hline & $\begin{array}{l}\text { Conglomerados y } \\
\text { areniscas (CH y SB) }\end{array}$ \\
\hline & Areniscas ( $D A$ y $S B$ ) \\
\hline $\begin{array}{ll}T & T_{T}^{\prime} \\
T\end{array}$ & Piroclastos $(P Y)$ \\
\hline 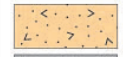 & $\begin{array}{l}\text { Piroclastos con areniscas, } \\
\text { conglomerados }\end{array}$ \\
\hline & Lutitas y areniscas (FF) \\
\hline
\end{tabular}

\begin{tabular}{|c|c|}
\hline & Localidad \\
\hline & $\begin{array}{l}\text { Ubicación del testigo } \\
\text { de perforación }\end{array}$ \\
\hline & $\begin{array}{l}\text { Datación radiométrica } \\
\text { (referencias) }\end{array}$ \\
\hline & $\begin{array}{l}\text { Datación radiométrica } \\
\text { (este estudio) }\end{array}$ \\
\hline & Cerro/lomada \\
\hline & Falla cartografiada \\
\hline & Falla inferida/lineamiento \\
\hline & Límite internacional \\
\hline & $\begin{array}{l}\text { Sentido general del } \\
\text { transporte sedimentario }\end{array}$ \\
\hline A-A & \\
\hline & $\begin{array}{l}\text { las Figs. } 4,5 \text { y } 6 \\
\text { las en }\end{array}$ \\
\hline
\end{tabular}

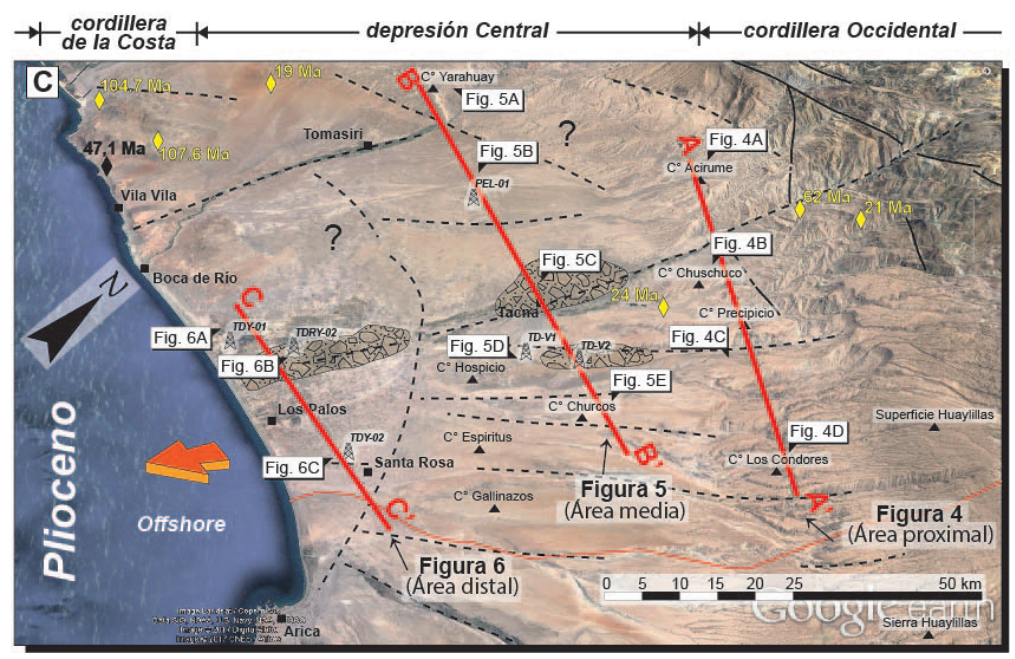

FIG. 7. Interpretación sedimentaria y distribución de facies sedimentarias en la cuenca Moquegua de la provincia de Tacna. A. Distribución espacial de las facies sedimentarias de la Formación Moquegua Superior (Oligoceno). B. Distribución de las facies de la Formación Huaylillas (Mioceno). C. Distribución de las facies sedimentarias de la Formación Millo (Plioceno). Las líneas punteadas negras señalan lineamientos que podrían tratarse de fallas normales sinsedimentarias de alto ángulo (mayores detalles en la Sección 6.4). Esta figura se refuerza con lo parametrado en la la tabla 3. 
Las facies de la Formación Huaylillas están representadas por el elemento arquitectural $P Y$ (piroclastos). Este elemento está comúnmente asociado (intercalado) con los elementos arquitecturales $\mathrm{CH}$, $D A$ y $S B$, y conforman un área muy extensa conocida como "Superficie Huaylillas" (Wilson y García, 1962). Esta asociación de elementos ocurre también en el norte de Chile (ignimbritas Diablo, Cardones y Oxaya, Tosdal et al., 1981; Marocco y Noblet, 1990; Wörner et al., 2000; García et al., 2004) y conforman superficies claramente visibles y muy bien conservadas desde finales del Mioceno (Evenstar et al., 2017) sin unidades litoestratigráficas que las cubran. Sin embargo, de acuerdo con la literatura, la Formación Millo (o Formacion Magollo de Flores y Sempere, 2002 in Flores et al., 2004) yace sobre la Formación Huaylillas. En Tacna, la ocurrencia de esta unidad es muy restricta. El único contacto observable entre esta unidad y la sobreyacente Formación Millo se halla en el cerro Magollo (Fig. 5C), y allí se observa que existe un límite erosivo muy marcado y posiblemente también diacrónico (ver Sección 5.1.3 para mayores detalles). Según France et al. (1984), Wörner et al. (2000) y Thouret et al. (2007), la edad de los depósitos de la Formación Huaylillas y sus contrapartes en el norte de Chile corresponde al intervalo Mioceno Inferior a Mioceno Superior (K-Ar en biotitas de piroclastos).

Interpretación. El elemento arquitectural $P Y$ es el más representativo de la actividad del Arco Volcánico Huaylillas (Mioceno, Mamani et al., 2010) y de mayor amplitud areal (Fig. 7B). Dada su asociación con los elementos arquitecturales $\mathrm{CH}, \mathrm{DA}$ y $S B$, los cuales son típicos de un ambiente fluvial, se interpreta que la sedimentación fluvial seguía siendo muy activa durante la actividad del citado arco volcánico. Por otro lado, el aumento de espesor estratigráfico de esta unidad hacia el norte de Chile puede deberse a su proximidad con los antiguos centros volcánicos del Mioceno.

\subsubsection{Facies sedimentarias en la Formación Millo (Formación Magollo), Plioceno}

Los afloramientos de esta unidad litoestratigráfica son escasos en Tacna. Afloran únicamente en el cerro Magollo (Fig. 5C) y localmente en el subsuelo de acuerdo con este estudio, aunque de modo muy restricto y sin espesores estratigráficos significantes (Fig. 6B). Estas rocas corresponden a conglomerados de textura clastosoportada, en su mayoría (facies $G c n$ )
(Fig. 3E), y en menor proporción a conglomerados clastosoportados por una matriz de arenisca (facies $G m n)$. Su asociación de facies refleja claramente al elemento arquitectural $\mathrm{CH}$. Adicionalmente, las rocas de la Formación Millo pueden contener facies compuestas de matriz de areniscas de grano grueso a medio con laminaciones oblicuas (facies $S x$ ) a manera de interbarras de menor escala $(<5 \mathrm{~m}$ de extensión lateral) (Fig. 3F), y se le considera como facies representativas del elemento arquitectural $D A$. Por lo tanto, en la Formación Millo es común encontrar asociaciones de los elementos $\mathrm{CH}$ y $\mathrm{DA}$.

Las facies de la Formación Millo son distinguibles de las subyacentes formaciones Huaylillas y Moquegua Superior por la composición litológica de sus clastos (i.e., predominio de clastos de andesitas y riolitas violáceos negruzcos derivados del Grupo Barroso, Decou et al., 2011; Alván et al., 2015) y por la coloración de la matriz de sus conglomerados (gris muy oscuro). Una característica adicional es que las facies sedimentarias de la Formación Millo demuestran haberse formado en un ambiente restricto y aun más canalizado que las subyacentes unidades, con bases erosivas más marcadas y con numerosas evidencias de fallamientos sinsedimentarios (Flores, 2004). Sin embargo, debido a que estas facies son de extensión areal muy reducida resulta complejo definir su evolución lateral con una resolución consistente. En Tacna y en el resto del sur de Perú (provincias de Arequipa y Moquegua), su edad depositacional es atribuida al Plioceno (Vargas, 1970; Sánchez et al., 2000; Sempere et al., 2004; Alván et al., 2015) (ver Sección 6.1 para mayores discusiones). Además, sus bases pueden ser diacrónicas (Sempere et al., 2014) debido a la escasa depositación de rocas sedimentarias asignadas a la Formación Millo o de cualquier unidad que pueda sobreyacer a la Formación Huaylillas (Evenstar et al., 2017).

Interpretación. Estos depósitos han sido definidos como elementos arquitecturales $\mathrm{CH}$ y $\mathrm{DA}$, y su asociación refleja claramente la ocurrencia de canales fluviales con organización multilateral. Se interpreta, además, que estos depósitos resultaron de la ocurrencia de flujos gravitacionales detríticos altamente canalizados, aparentemente de mayor energía de transporte que los interpretados en las subyacentes formaciones Moquegua y Huaylillas. Las facies de la Formación Millo son las más escasas de las rocas cenozoicas que se observan en Tacna, y su distribución areal es coincidente con el lineamiento 
del recorrido del río Caplina (Lineamiento Caplina, Acosta et al., 2012). La naturaleza de estos flujos muestra signaturas sedimentarias similares al de una depositación tipo flash-flood, que rellenan los paleovalles y quebradas prominentes. En tal contexto, se interpreta que la sedimentación de este tipo es la de un "paleorrío" de similar trayecto que el actual río Caplina. La Formación Millo no representa significancia volumétrica en los afloramientos ni en el subsuelo de Tacna y La Yarada. La conservación de la paleosuperficie conocida como "Superficie Huaylillas" a lo largo del sur de Perú y norte de Chile es un claro reflejo de la escasa extensión areal de los procesos sedimentarios que dieron origen a la Formación Millo (Fig. 7C). Se interpreta, además, que la abundancia de fallas sinsedimentarias en esta unidad litoestratigráfica también puede ser un elemento útil para su distinción y reconocimiento.

\subsection{Minerales pesados en las rocas cenozoicas de Tacna}

Los resultados del análisis de minerales pesados complementan los provistos por Bustamante (2017) en el área de Tacna y se apoyan, además, en trabajos similares realizados en otras partes de la cuenca Moquegua por Decou et al. (2011,
2013) y Alván et al. (2015), quienes realizaron tales análisis en estratos de las mismas unidades litoestratigráficas en las provincias de Moquegua (ca. $100 \mathrm{~km}$ al noroeste de Tacna) y Arequipa (ca. $250 \mathrm{~km}$ al noroeste de Tacna). Este estudio se basa en el análisis de 43 muestras de areniscas de grano medio, tanto de las rocas cenozoicas en estudio como de las del basamento de la cuenca, y 6 muestras de rocas intrusivas y volcánicas obtenidas de afloramientos y testigos de perforación (Tabla 1). En el conteo de minerales pesados se ha excluido a las epidotas, óxidos de hierro y cloritas, debido a que la mayor parte de las rocas del área de estudio han sido ampliamente afectadas por alteración propilítica. Posteriormente, con el afán de mejorar en la visualización de los espectros minerales, se ha visto conveniente separar visualmente también a los anfíboles y apatitos, debido a que también se encuentran en casi todas las unidades litológicas (ver Sección 6.3 para mayores discusiones).

Se presentan espectros de minerales pesados para las rocas de las formaciones Moquegua Superior, Huaylillas y Millo, obtenidos a partir de los resultados normalizados al $100 \%$. Tales espectros se representan en las figuras 8 y 9 , donde la figura 8 corresponde a espectros de muestras tomadas de los afloramientos presentes en los cerros y lomadas alrededor de Tacna,

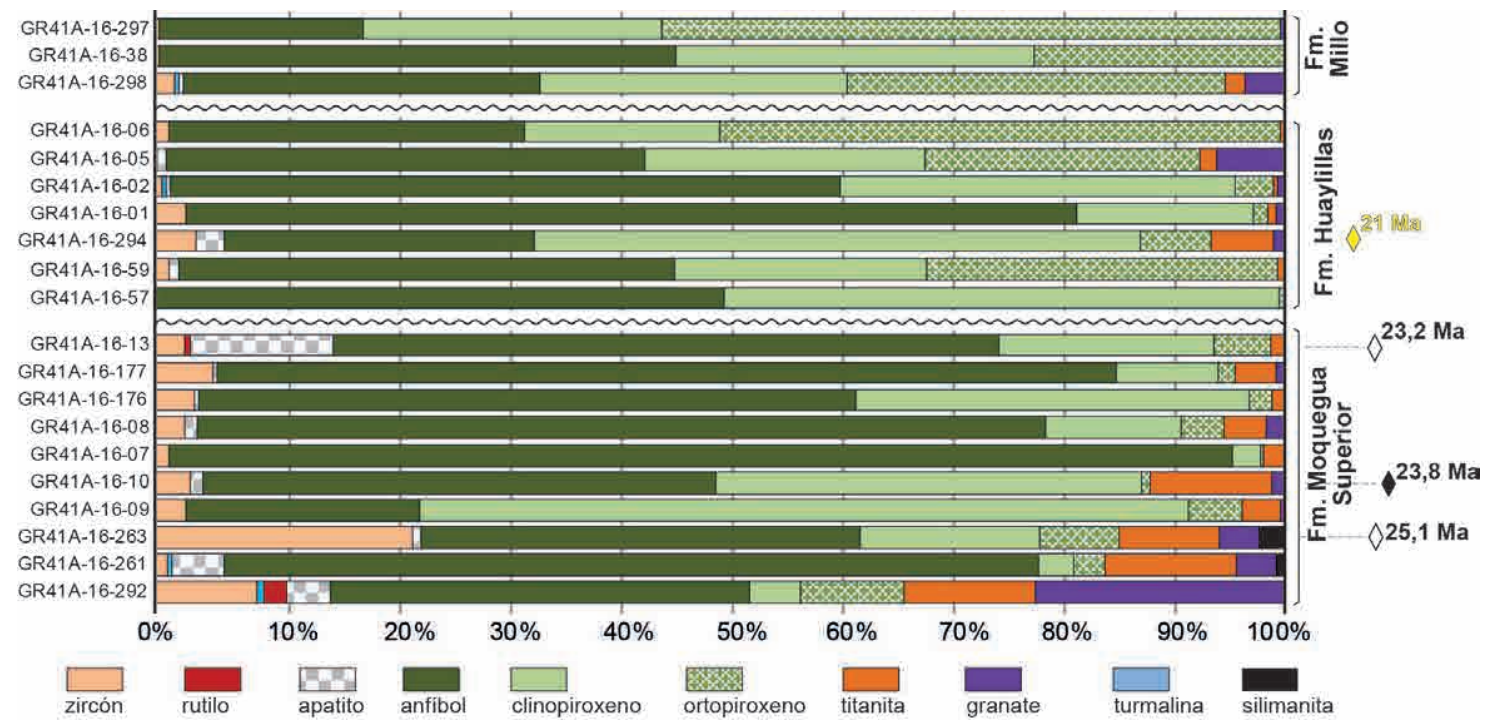

FIG. 8. Espectros de minerales pesados de las formaciones Moquegua, Huaylillas y Millo correspondientes a muestras de afloramientos $\left(\mathrm{n}_{\text {muestras }}=20\right)$. Véase la composición litológica de las muestras en la tabla 1. Las dataciones previas (rombos) provienen de Bellón y Lefevre (1976), Vatin-Perignon et al. (1996) y Quang et al. (2005). Para ver las dataciones de este estudio (rombos negros y blanco) refiérase a la tabla 4. 


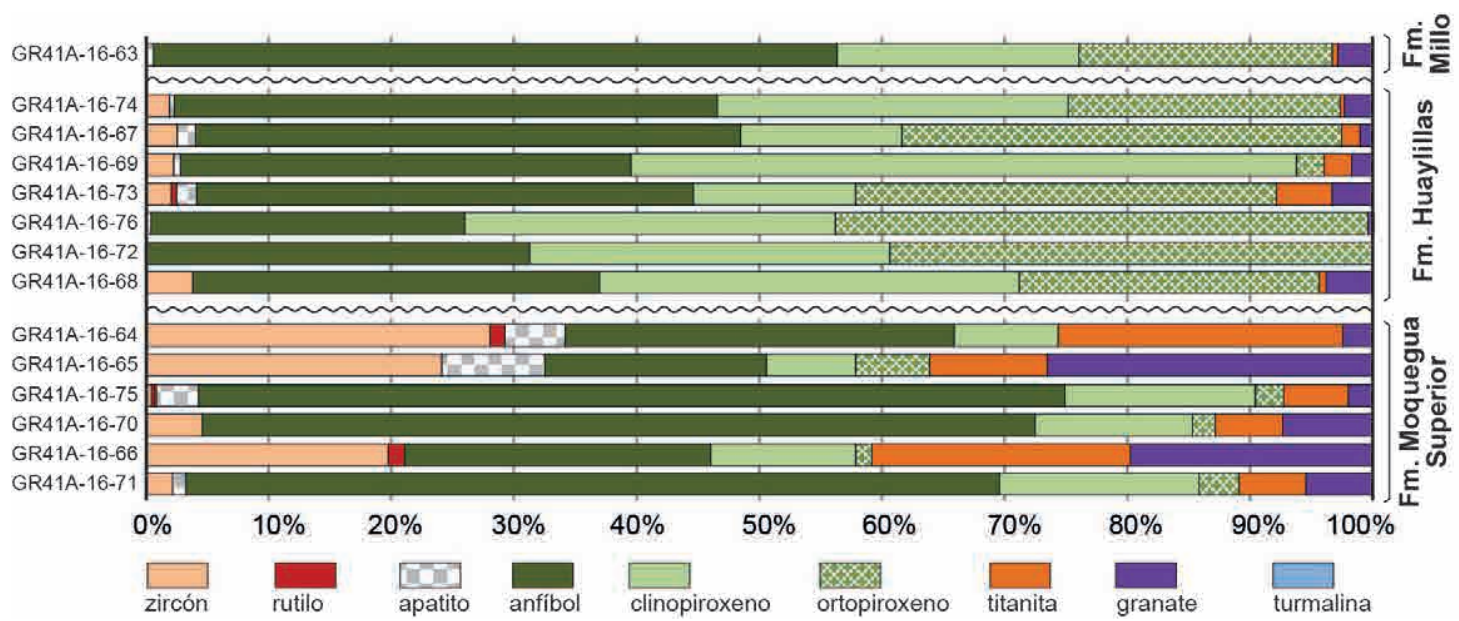

FIG. 9. Espectros de minerales pesados de las formaciones Moquegua, Huaylillas y Millo correspondientes a muestras de testigos de pozos de perforación $\left(\mathrm{n}_{\text {muestras }}=14\right)$. Véase ubicación de los testigos de perforación en la figura 2 y la composición litológica de las muestras en la tabla 1. Nótese la correspondencia estratigráfica con los espectros presentados en la figura 8.

y la figura 9 de los testigos de pozos de perforación realizados en Tacna y La Yarada. A grandes rasgos, los espectros de las figuras 8 y 9 son similares, debido a que responden a unidades correlacionables (ver Sección 6.2 para más información).

Según se observa en la parte inferior de las figuras 8 y 9, los sedimentos de la Formación Moquegua Superior (tanto en afloramientos como en los testigos de pozos) se caracterizan por contener abundantes anfíboles y circones ( $>50 \%$ ), seguido de granates, titanitas, y en menor proporción clinopiroxenos y apatitos. Esta asociación mineral resulta ser muy útil para describir esta unidad, debido a que solo se presenta en estos depósitos. Sobre un contacto erosivo se disponen las rocas piroclásticas y sedimentarias de la Formación Huaylillas y ofrecen un marcado cambio litológico y de facies. Tales facies se caracterizan por un drástico aumento del contenido de clinopiroxenos (hasta $42 \%$ ), seguido de ortopiroxenos. Los anfíboles también son minerales abundantes en las rocas de la Formación Huaylillas, aunque subordinados a los piroxenos. Se observa, además, titanitas, granates y circones en proporciones menores; sin embargo, estos últimos no caracterizan a esta unidad. Por último, sobre un nuevo contacto erosivo y diacrónico yacen los sedimentos de la Formación Millo, los cuales se distinguen también por su alto contenido de anfíboles y piroxenos, y muestran como minerales subordinados a las titanitas y granates. Como se observa en las figuras 8 y 9 , el contenido mineral de las formaciones Huaylillas y
Millo son similares; sin embargo, se les diferencia por su contenido litológico. Es decir, la abundancia de piroclastos rosáceos estratificados y clastos de andesitas caracterizan a la Formación Huaylillas, mientras la presencia de conglomerados con clastos de riolitas y coloración gris oscura es típica de la Formación Millo.

Después de caracterizar las unidades litoestratigráficas cenozoicas, ha sido posible identificar espectros de minerales pesados similares entre las muestras colectadas en superficie y las colectadas en los testigos de pozos de perforación. Esta particularidad representa una herramienta de gran ayuda para sustentar correlaciones estratigráficas entre los dominios citados, así como también visualizar la existencia de posibles fallas normales de alto ángulo en el subsuelo de Tacna (Martínez et al., 1996) como se sugiere en las figuras 4, 5 y 6 (mayores detalles y discusiones en la Sección 6.3).

\subsection{Minerales pesados en las rocas del basamento de la cuenca Moquegua en Tacna}

Las rocas más antiguas del basamento de la cuenca Moquegua corresponden a gneises y ortogneises del Complejo Basal de la Costa (CBC) o también conocido en el sur de Perú como Basamento Metamórfico Mal Paso (BMMP) del Proterozoico (Wilson y García, 1962), mientras las más jóvenes de estas rocas están representadas por la Unidad intrusiva Challaviento del Eoceno Medio. 
Sus espectros minerales se muestran en la figura 10, donde se observa que las rocas del CBC contienen abundantes granates (hasta $42 \%$ del espectro) y cantidades subordinadas de circones subredondeados $(\sim 18 \%)$, titanitas incoloras $(\sim 15 \%)$ y ortopiroxenos $(\sim 12 \%)$, entre otros. Las areniscas del Grupo Ambo (Carbonífero) contienen circones subredondeados y con frecuencia redondeados, los que son predominantes en este espectro (hasta $42 \%$ ). Este grupo también se caracteriza por contener hasta un $30 \%$ de titanitas incoloras y rutilos $(\sim 8 \%$ de su espectro). Las areniscas del Grupo Yura y de la Formación Hualhuani tienen una composición mineralógica similar a la del Grupo Ambo, aunque con mayor proporción de turmalinas (alto índice ZTR, circón-turmalina-rutilo, cf. Hubert, 1962; Trinidad, 2017), granates y anfíboles. Las andesitas de la Formación Junerata/Chocolate se caracterizan por su alto contenido de clinopiroxenos, ortopiroxenos y apatitos, y contrastan ampliamente con las anteriores. En Tacna, estas rocas han sido intensamente afectadas por alteración propilítica, lo que da como resultado significantes cantidades de epidotas y granates. La presencia de tales minerales no corresponde a lo observado en los minerales accesorios típicos de las andesitas y basaltos (Mange y Maurer, 1992), por lo tanto, han sido descartados de este análisis. El Grupo Toquepala (andesitas) es claramente diferenciable de los anteriores por su alto contenido de ortopiroxenos (hasta 35\%), aun más abundantes que lo observado en las andesitas de la Formación Junerata/Chocolate. Por último, la Unidad intrusiva Challaviento en Tacna (Eoceno Medio) se compone de dioritas y se caracteriza por su amplia predominancia de anfíboles frescos (hasta $\sim 90 \%$ ) y circones euhedrales incoloros.

\subsection{Proveniencia de los sedimentos cenozoicos de la cuenca Moquegua en el área de Tacna}

Según la información mineralógica, los sedimentos de la Formación Moquegua Superior en Tacna provienen predominantemente de la exhumación y denudación de las rocas del Complejo Basal de la Costa (CBC), del Grupo Ambo y de la Formación Junerata/Chocolate (ver esquematización en la Fig. 11A). Esto es consistente con algunas edades $\mathrm{U}-\mathrm{Pb}$ en circones detríticos cercanas a $560 \mathrm{Ma}$ y $\pm 1,820 \mathrm{Ma}$ (aunque no ploteadas en la Fig. 12) obtenidas en este estudio (muestra GR41A-16-10), las cuales permiten confirmar la influencia de la citada fuente metamórfica (CBC). Dada la abundancia de titanitas, granates, clinopiroxenos (como se sugiere en la Fig. 11A) y un moderado índice GZ (granate-circón, Hubert, 1962) en las rocas parentales caracterizadas, es adecuado sugerir

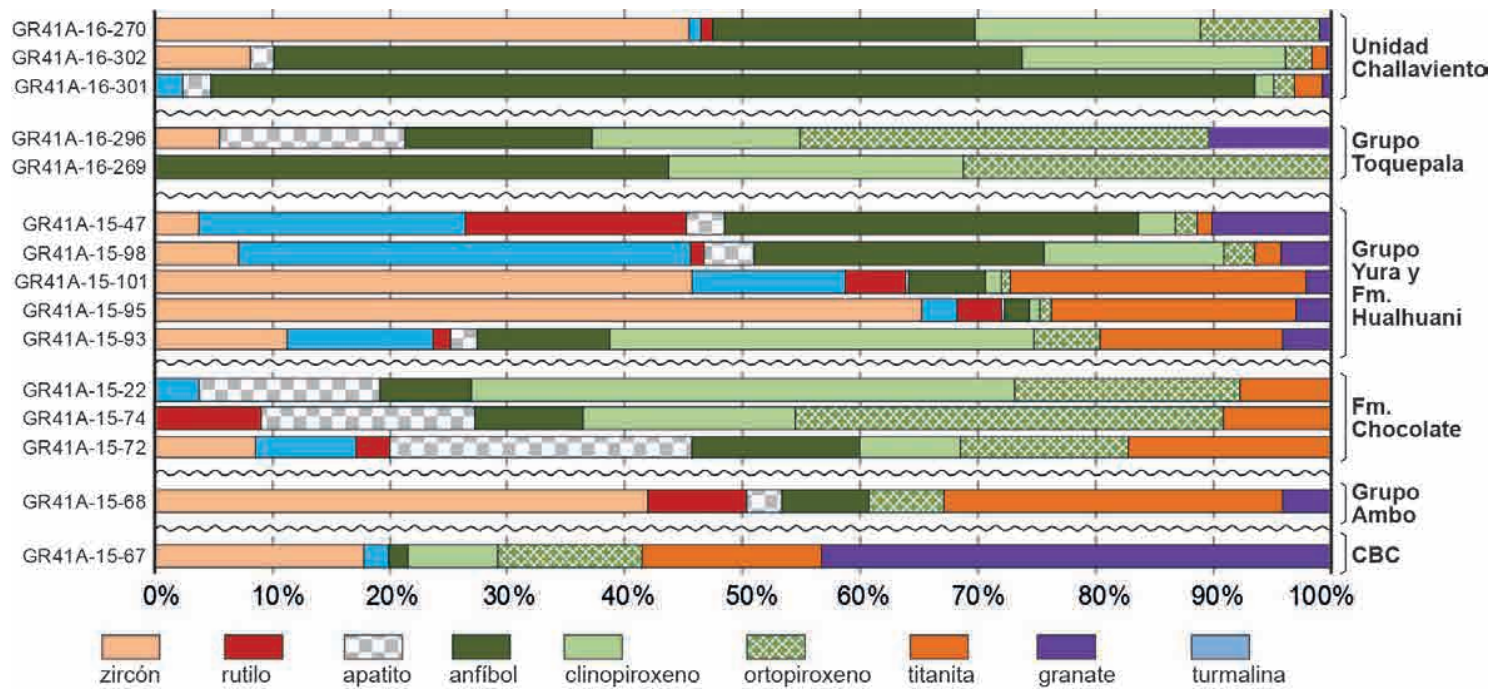

FIG. 10. Espectros de minerales pesados del basamento de la cuenca Moquegua en Tacna $\left(\mathrm{n}_{\text {muestras }}=15\right)$. Estas rocas fueron colectadas de afloramientos ubicados en la cordillera Occidental de Tacna (tomado de Bustamante, 2017 y Trinidad, 2017). Véase la composición litológica de las muestras en la tabla 1. 

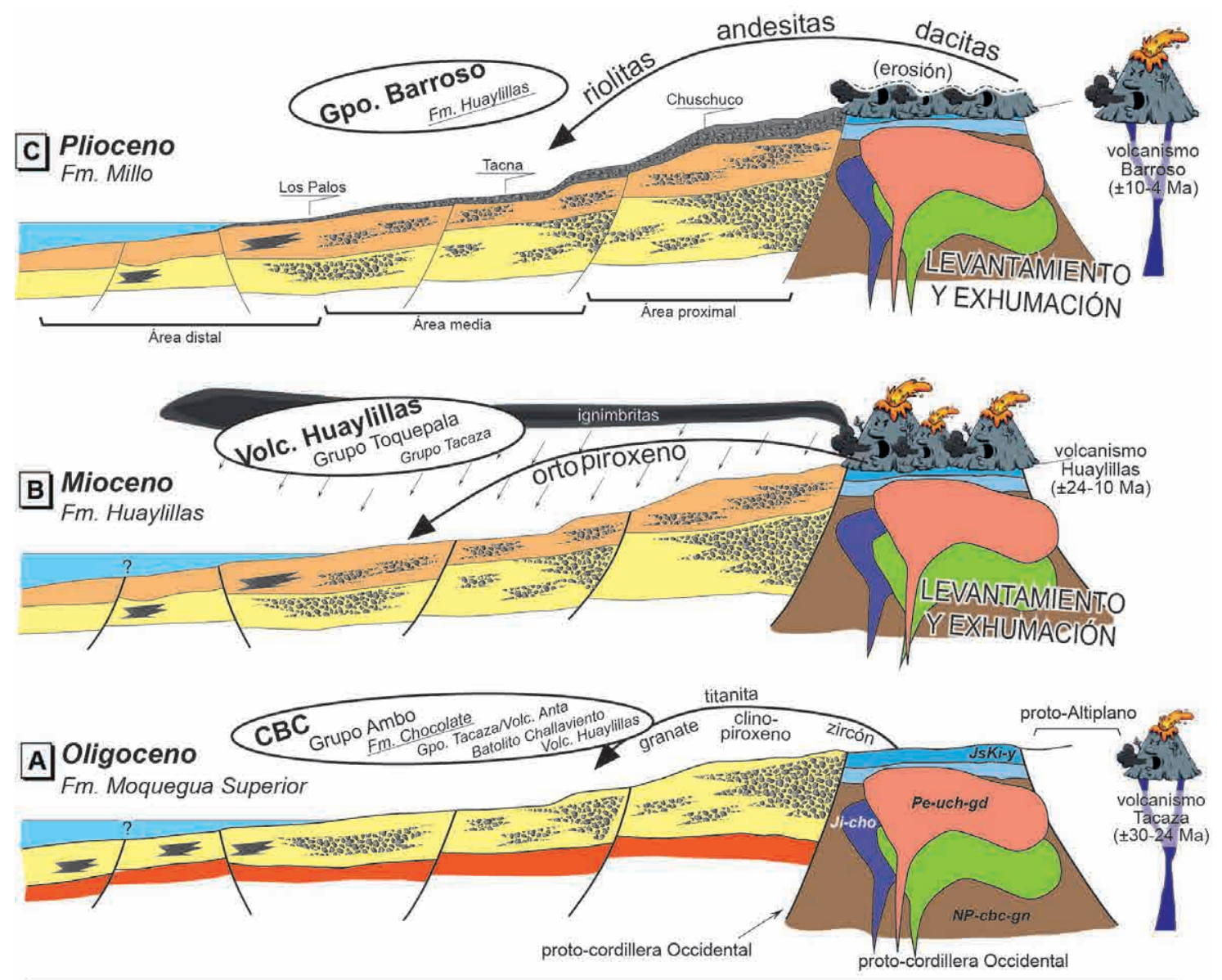

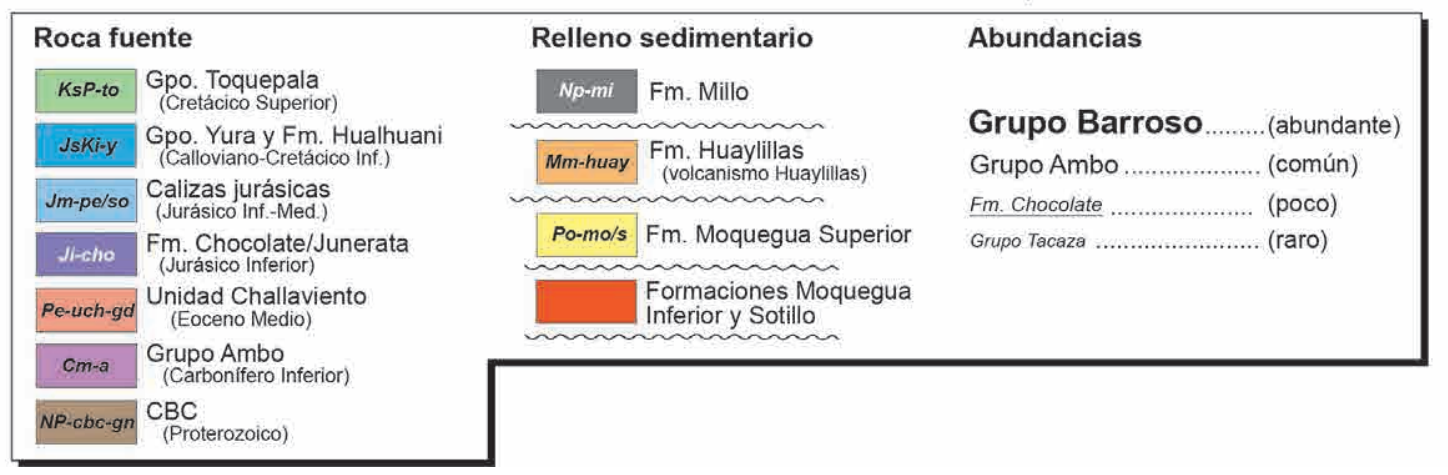

FIG. 11. Modelo de proveniencia sedimentaria de las rocas cenozoicas de Tacna basado en los espectros de minerales pesados elaborados por Bustamante (2017) y robustecido con los datos de este estudio. Nótese la propuesta de distribución de las facies en las áreas depositacionales. La organización estructural ha sido inspirada en Noury et al. (2017).

que estas dominaban en volumen y/o extensión la cordillera Occidental en Tacna durante el Oligoceno. Las edades $\mathrm{U}-\mathrm{Pb}$ en circones detríticos provistos en la figura 12 arrojan edades similares a las del Arco Volcánico Anta y a la Unidad intrusiva Challaviento
(30-42 Ma y 42-55 Ma, respectivamente, Mamani et al., 2010), lo cual permite afirmar que, al menos, parte los aportes detríticos también provienen de las citadas roca-fuente y por lo tanto, pudo provenir desde el Altiplano. 


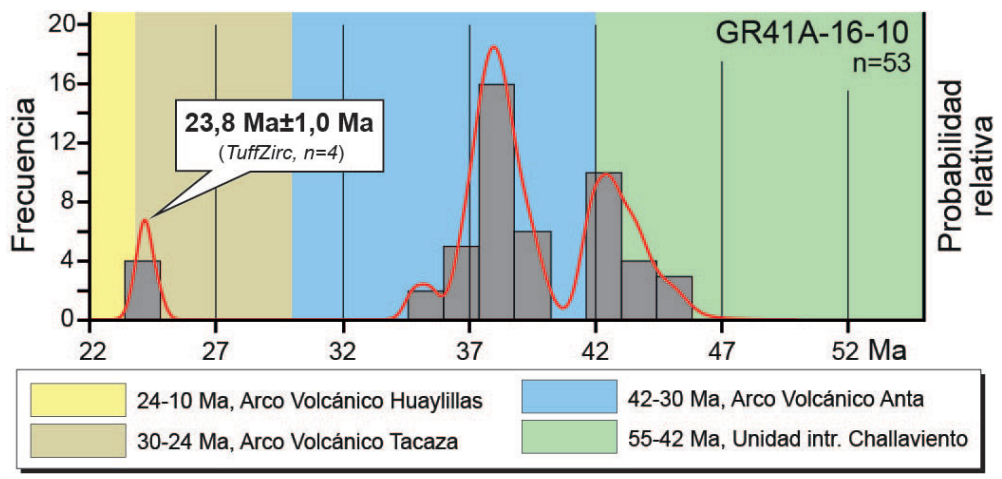

FIG. 12. Edad depositacional de las rocas sedimentarias de la parte superior de la Formación Moquegua Superior en Tacna (muestra GR41A-16-10, arenisca) por el método U-Pb en circones detríticos. Se aprecian, además, edades más antiguas que ayudan a identificar la proveniencia de los sedimentos. Las edades más jóvenes fueron definidas con los métodos Density Plotter y PopShare (Dunkl y Székely, 2002; Vermeesch, 2012). Se aplicó el método TuffZirc (Ludwig, 2003) cuando el número de las edades de los granos individuales lo permitieron.

El término de la depositación de las rocas de la Formación Moquegua Superior, aunque es gradual, es posible trazarlo en la cartografía y en la estratigrafía. Se presenta una propuesta de primer cambio en el espectro de minerales pesados y en la proveniencia del material detrítico (línea roja inferior en la figura 13), la cual representaría un cambio importante en la geodinámica y exhumación de rocas parentales adicionales. Según su composición mineral, se puede afirmar que los depósitos piroclásticos y la fracción detrítica de las rocas de la Formación Huaylillas derivaron, principalmente, de la erupción y el retrabajamiento de las ignimbritas del Arco Volcánico Huaylillas (Mioceno, Mamani et al., 2010) (Fig. 11B). Además, es notoria y característica la abundancia de ortopiroxenos y anfíboles en estos depósitos, lo cual permite postular que una porción significativa de detritos proviene de la denudación de las rocas volcánicas del Grupo Toquepala en la cordillera Occidental. Tal retrabajamiento sedimentario trae consigo componentes adicionales del Grupo Tacaza.

Una vez terminada la depositación de las rocas de la Formación Huaylillas se aprecia un segundo cambio en la composición del espectro de minerales pesados y en la proveniencia del material detrítico (línea roja superior en la Fig. 13). Los sedimentos que componen las rocas de la Formación Millo iniciaron su depositación hace $c a$. 5 Ma con un nuevo y drástico cambio de facies y de composición. Esta depositación es contemporánea a un último pulso de deformación asociado con cambios en la subducción, el cual sería el responsable de la última etapa de deformación de los Andes, de la elevación del actual Altiplano (cf. Mahlburg-Kay y Mpodozis, 2002; Oncken et al., 2006; Horton, 2018) y de la depositación de la Formación Millo en el resto del sur del Perú (Decou et al., 2013; Alván et al., 2015) (ver Sección 6.2 para mayores discusiones). En ese contexto, se propone que los sedimentos de la Formación Millo en Tacna también derivaron de la denudación de las rocas del Altiplano, i.e., Grupo Barroso (riolitas, andesitas y piroclastos, Mamani et al., 2010) y parcialmente de las rocas de la Formación Huaylillas, las cuales le subyacen inmediatamente (Fig. 11C). Las rocas de la Formación Millo, además de contener abundantes clastos de riolitas y andesitas, se distinguen por una marcada disminución de titanitas y granates, similar a lo sugerido por Decou et al. (2011) en la provincia de Arequipa. A pesar de ser este proceso sedimentario producto de un evento geodinámico tan importante, la depositación de la Formación Millo no es volumétricamente significativa en Tacna y su ocurrencia es muy esporádica.

\section{Discusión}

\subsection{Edades depositacionales y límites estratigráficos}

Este estudio presenta un conjunto de nuevas dataciones realizadas por los métodos $\mathrm{U}-\mathrm{Pb}$ y (U-Th)/He en circones detríticos, y permite refinar la edad de la Formación Moquegua Superior. Tales circones se obtuvieron en sedimentos de la parte superior de esta unidad litoestratigráfica 


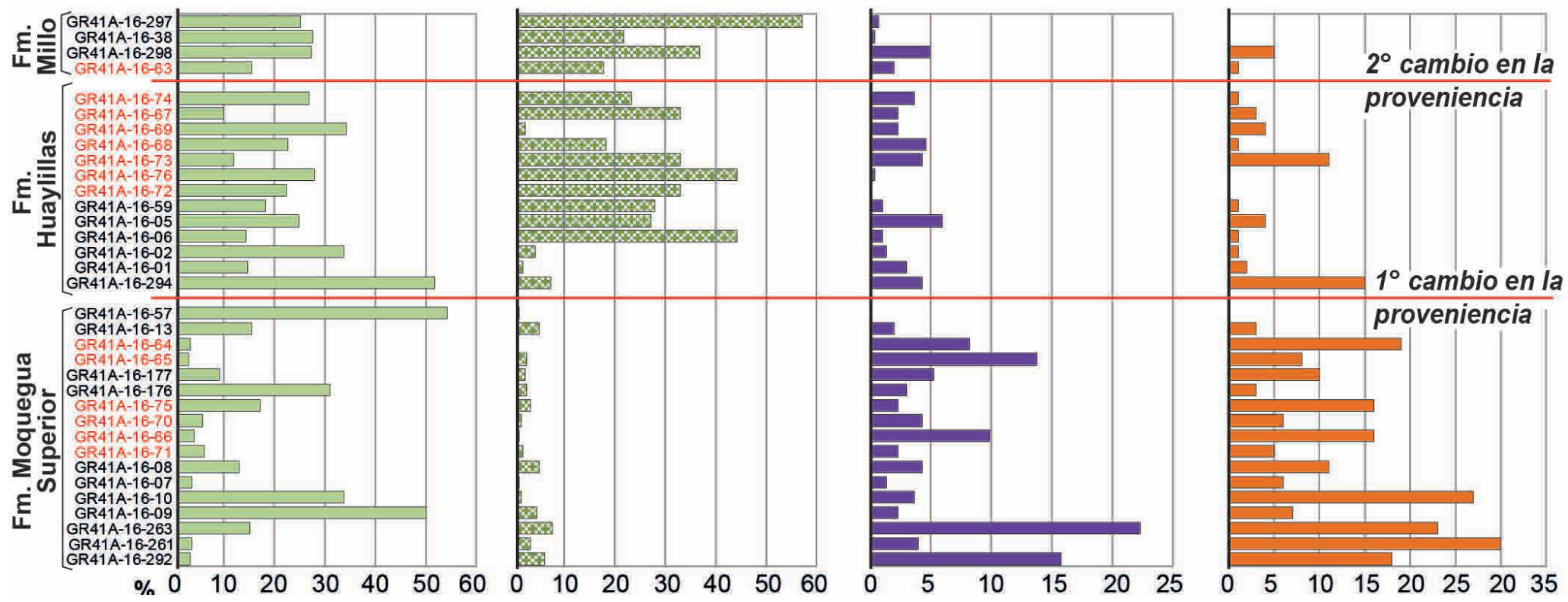

FIG. 13. Grupos de minerales pesados más representativos de las rocas sedimentarias cenozoicas de Tacna. Muestras en rojo: muestras colectadas de testigos de pozos de perforación, y en negro: muestras de afloramientos. Nótese la definición de dos cambios drásticos en el espectro mineralógico de las rocas sedimentarias cenozoicas del área de Tacna, los cuales coinciden con cambios en las unidades estratigráficas y fuente de origen de los sedimentos (líneas horizontales rojas). Esta información ha sido extraída de las figuras 8 y 9. 
(parte basal del cerro Churcos), e indica edades de 23,8 Ma (muestra GR41A-16-10, Fig. 13) y 23,2 Ma (muestra GR41A-16-248) (Fig. 5E). Ellas sugieren que la edad depositacional mínima de la Formación Moquegua Superior corresponde a la etapa más tardía del Oligoceno. Tomando en consideración que existen algunos estratos de rocas piroclásticas en la parte superior de la Formación Moquegua Superior, se puede considerar a estos niveles como resultado del inicio de la actividad del Arco Magmático Huaylillas (Mamani et al., 2010). Tal afirmación puede resultar confusa al momento de definir un límite estratigráfico para esta formación; sin embargo, en términos cartográficos y estratigráficos, el techo de la Formación Moquegua Superior está definido por el término de las facies de areniscas y conglomerados (facies $S x, S m$ y Gmn). En conclusión, la edad depositacional más joven de la Formación Moquegua Superior sería ca. $23 \mathrm{Ma}$; mientras que, por referencias, la edad más antigua puede ser considerada como del Oligoceno Inferior (Decou et al. (2011). Tales resultados son consistentes con lo sugerido por Flores et al. (2004), quienes propusieron el Oligoceno para la Formación Moquegua Superior sobre la base de algunas dataciones radiométricas $\mathrm{K}-\mathrm{Ar}$ que realizaron Sempere et al. (2014) en la subyacente Formación Moquegua Inferior y con la edad oligocena-miocena propuesta por Wilson y García (1962) y Sánchez et al. (2000).

La edad depositacional de la Formación Huaylillas y sus contrapartes en el norte de Chile (formaciones Oxaya y El Diablo) está restringida al Mioceno de acuerdo con a numerosas dataciones K-Ar en biotitas de piroclastos (e.g., France et al., 1984; Wörner et al., 2000; Thouret et al., 2007; Mamani et al., 2010). Sin embargo, el tope de esta unidad es diacrónico debido a la marcada erosión que provocó la depositación de la Formación Millo (Sempere et al., 2014). Los conglomerados de la Formación Millo son producto de la denudación de las andesitas y riolitas que componen la Formación Barroso (Plioceno), y se considera que su depositación en la cuenca Moquegua al oeste se debe a un último cambio drástico en la subducción ocurrido a los $c a .5 \mathrm{Ma}$, donde Mahlburg-Kay y Mpodozis (2002) y Oncken et al. (2006) reportan una última etapa de engrosamiento cortical, alzamiento y denudación de los arcos volcánicos con una significativa generación de detritos. Este episodio citado ha posibilitado la erosión casi exclusivamente las rocas de la Formación Barroso poco después de su depositación. Por lo tanto, este estudio considera una edad pliocena para la Formación Millo.

\subsection{Proveniencia del aporte sedimentario durante el Cenozoico en Tacna y en el resto de los Andes centrales}

Decou et al. (2011) realizaron los primeros estudios de minerales pesados cenozoicos en el sur de Perú con la finalidad de definir la proveniencia del material sedimentario, precisamente en la provincia de Moquegua (aproximadamente $100 \mathrm{~km}$ al noroeste de Tacna), mientras que Alván et al. (2015) presentaron también un modelo de proveniencia más al norte (Camaná, provincia de Arequipa). Hacia el norte de Chile, Wotzlaw et al. (2011) definieron la proveniencia sedimentaria de las rocas de la Formación Azapa (Oligoceno medio a Mioceno Inferior, Wörner et al., 2000), aportando antecedentes sobre gran parte de la historia depositacional cenozoica en el antearco de los Andes Centrales, como se integra en la figura 14.

Con base en el análisis de minerales pesados y geocronología de detritos, Decou et al. (2011) afirmaron que los sedimentos de la Formación Moquegua Superior en la localidad de Moquegua provienen de la denudación de las rocas del Grupo Yura, Batolito de la Costa y parcialmente del Complejo Basal de la Costa (Proterozoico). Con los mismos métodos, Decou et al. (2013) y Alván et al. (2015) demostraron que los sedimentos de la Formación Moquegua Superior en Arequipa tienen fuentes muy similares, aunque en proporciones variables. En el extremo norte de Chile, Horton et al. (2007) y Wozlaw et al. (2011) sugirieron que los sedimentos oligocénicos del antearco (Formación Azapa) derivaron predominantemente de la erosión del Complejo Metamórfico Belén (CMB, Proterozoico) y subordinadamente de las cuarzoarenitas mesozoicas del Altiplano (equivalentes al Grupo Yura). Comparando las roca-fuentes definidas en este estudio, podemos afirmar que en Tacna las rocas que estuvieron exhumadas y fueron denudadas durante el Oligoceno fueron similares, así como también el proceso geodinámico que las afectó.

Respecto a las formaciones Huaylillas y Oxaya, Wilson y García (1962), Mamani et al. (2010) y Acosta et al. (2012) coincidieron en que el material piroclástico de estas unidades proviene de la actividad volcánica del Arco Huaylillas (Mioceno) y su equivalente volcanismo Oxaya (Wörner et al., 2000), respectivamente. Según Haschke et al. (2006), tal 


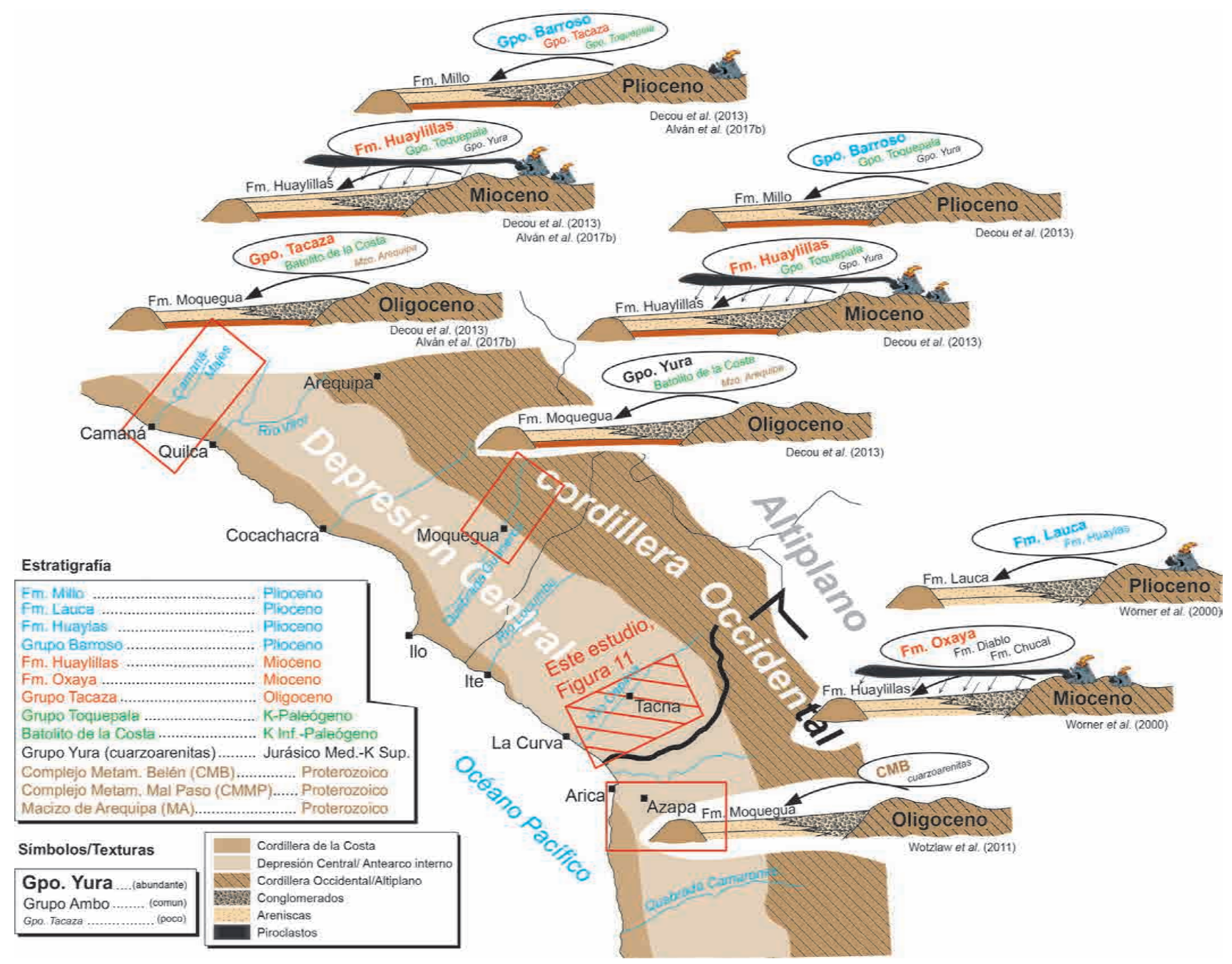

FIG. 14. Historias depositacionales y proveniencia sedimentaria del sur del Perú y norte de Chile desde el Oligoceno al Plioceno, según la información disponible en Wörner et al. (2000) y Wotzlaw et al. (2011) para el valle de Azapa (norte de Chile), y los modelos de Decou et al. (2013) (para el valle de Moquegua) y Alván et al. (2015, 2017b) (para el valle de MajesCamaná), en los cuadros rojos. El recuadro "Este estudio" hace mención a la figura 11. 
volcanismo es atribuible a un marcado incremento en el ángulo de subducción de la placa oceánica, acompañado también por un importante acortamiento cortical, lo cual es consistente con la abundante acumulación de conglomerados que se intercalan con los productos volcánicos preferentemente en la parte distal de la cuenca Moquegua. Por último, la Formación Millo guarda en su parte inferior detritos provenientes de la denudación de la Formación Huaylillas, como también lo consideran Decou et al. (2013) y Alván et al. (2015), lo que permite interpretar que los procesos sedimentarios que originaron las rocas de la Formación Millo están más vinculados a los procesos de deformación y denudación que a las etapas de depositación volcánica; es decir, la parte inferior de la Formación Millo carga los productos de la denudación de las últimas etapas de actividad del volcanismo Huaylillas (Mioceno) y/o del inicio del volcanismo Barroso (Plioceno), y finalmente, se completa con la denudación de las rocas volcánicas de la Formación Barroso.

\subsection{Elementos de correlación entre las unidades cenozoicas aflorantes y del subsuelo de Tacna}

Los resultados del presente estudio permiten afirmar que las rocas cenozoicas aflorantes en el área de Tacna (e.g., cerros Yarahuay, Magollo, Precipicio, Acirume, Churcos, Chuschuco, Hospicio, Espíritus, Gallinazos, entre otros, Figs. 4, 5 y 6) son correlacionables con las que yacen en el subsuelo del área de Tacna y La Yarada, y se disponen como se sugiere en las figuras 4, 5 y 6 . Esta afirmación se basa en los resultados del estudio del contenido de minerales pesados en cada unidad litológica. Sin embargo, estas señales en la composición mineral se pueden ver mejor si suprimimos visualmente los anfíboles y otros minerales que aparecen en casi todas las muestras, como se aprecia en la figura 13. Según esta figura, los sedimentos de la Formación Moquegua Superior se caracterizan por su alto contenido de titanitas (incoloras) y granates en comparación con lo observado en los espectros minerales de las sobreyacentes formaciones Huaylillas y Millo. Además, el índice GZ (granate-circón, Morton y Hallsworth, 1999) de la Formación Moquegua Superior (figura 13) también es alto, y permite distinguir esta unidad en relación a las otras que la sobreyacen, tanto en las muestras de afloramientos como en las de los testigos.
Las rocas de las formaciones Huaylillas y Millo se caracterizan por contener una cantidad excepcional de ortopiroxenos, lo cual contrasta con la ausencia de este mineral en las rocas sedimentarias de la Formación Moquegua Superior. Este arreglo mineral se cumple en todas las muestras de las columnas estratigráficas elaboradas en los afloramientos y de los testigos de perforación del área de Tacna y La Yarada (Figs. 8 y 9), y cumple también con las expectativas como "espectros de minerales guías" para establecer correlaciones estratigráficas entre los estratos cenozoicos de Tacna. En consecuencia, las correlaciones estratigráficas presentadas en las figuras 4, 5 y 6 están respaldadas por los espectros minerales y permiten proponer que el subsuelo de Tacna y La Yarada está conformado por rocas correspondientes a las formaciones Huayllilas y Moquegua Superior. Esta conclusión permite, además, postular la existencia de fallas normales de alto ángulo que producen un desplazamento vertical (de al menos $200 \mathrm{~m}$ ) entre las secuencias estratigráficas aflorantes y aquellas presentes en el subsuelo de las planicies de La Yarada y Los Palos. Esto es consistente con lo expuesto en las secciones sísmicas interpretadas por Martínez et al. (1996) en el subsuelo de La Yarada, en las cuales reconocen la existencia de fallas con comportamiento estructural normal, con alto ángulo (líneas punteadas en las Figs. 4, 5 y 6) y hasta con cierto basculamiento, los cuales tienen influencia en la actual morfología (lomas elevadas y planicies extensas). Concordante con esta interpretación, las rocas sedimentarias que yacen en el subsuelo del área de Tacna y sus posibles contrapartes en offshore tienen edad cenozoica (Alván et al., 2017a), y no cuaternaria como se propone en PET (2007).

\section{Conclusiones}

Las facies sedimentarias reconocidas en las rocas cenozoicas del área de Tacna y su distribución areal, junto con la identificación de las fuentes de aportes de los sedimentos y la edad depositacional de los mismos permiten concluir lo siguiente:

- La definición de la arquitectura depositacional cenozoica en conjunto con los espectros de minerales pesados y la edad de depositación de las secuencias de rocas sedimentarias han permitido generar un modelo cronoestratigráfico para las rocas cenozoicas del área de Tacna, donde la edad mínima de depositación de la Formación Moquegua Superior alcanza los ca. $23 \mathrm{Ma}$. 
- Las asociaciones de minerales pesados de las rocas sedimentarias del Cenozoico en el área de Tacna (cuenca Moquegua) indican que la principal fuente de aporte de sedimentos durante el relleno de la cuenca se localizaba hacia el este de la misma, en la actual cordillera Occidental y el altiplano.

- El análisis de la proveniencia sedimentaria (resumido en la Fig. 11) resuelve que los sedimentos que dieron origen a las rocas sedimentarias de la Formación Moquegua Superior (Oligoceno) en Tacna fueron aportados por la erosión de las rocas del Complejo Basal de la Costa (Proterozoico), la Unidad intrusiva Challaviento (Paleógeno), el Grupo Ambo (Carbonífero) y la Formación Junerata/Chocolate (Jurásico Inferior). En tanto, las rocas de la Formación Huaylillas (Mioceno) se vinculan en su origen con la actividad del arco volcánico del Mioceno (Arco Volcánico Huaylillas) y la denudación de las rocas volcánicas del Grupo Toquepala. Los sedimentos que dieron origen a las rocas de la Formación Millo (Plioceno) fueron aportados por la erosión de las rocas que constituyen el Grupo Barroso (Mioceno SuperiorPlioceno), ubicado en el altiplano, y parcialmente de la Formación Huaylillas.

- En Tacna, las facies sedimentarias identificadas en las rocas de la Formación Moquegua Superior (Oligoceno) son compatibles con depósitos fluviales originados por la actividad de un sistema de ríos trenzados. En esta formación tienen predominancia los elementos arquitecturales $C H$ y $S B$ (y/o $D A$ ) en su parte proximal, mientras en su parte distal abundan los elementos $D A$ (y/o $S B)$ y $F F$. La Formación Huaylillas (Mioceno) se caracteriza en su zona proximal por la predominancia de depósitos piroclásticos (elemento $P Y$ ) y por la esporádica aparición de los elementos $C H$ y $S B$ (y/o $D A$ ) preferentemente en la parte media de la cuenca. En tanto en su parte más distal priman los elementos $D A$ (y/o $S B$ ) y $F F$. La Formación Millo consiste en depósitos conglomerádicos canalizados (elemento $\mathrm{CH}$ ) que estuvieron ampliamente afectados por fallas sinsedimentarias. Tales depósitos estuvieron restrictos a lo largo de los valles, lineamientos o fallas más grandes, i.e., Falla Caplina, y en algunas partes del subsuelo (Pozo TDRY-02, Fig. 6B).

- Las abundancias relativas de granate, titanita y circón (subredondeado) caracterizan a los sedimentos de la Formación Moquegua Superior, tanto en los afloramientos como en los testigos de perforación; mientras que la abundancia de ortopiroxenos a las formaciones Huaylillas y Millo en las mismas condiciones (Fig. 13). La Formación Millo se diferencia de la Formación Huaylillas por sus litofacies (conglomerados con clastos de andesitas y riolitas) y por su escasez de piroclastos en comparación con la alta concentración de los mismos observados en las rocas de la Formación Huaylillas. En ese contexto, las rocas cenozoicas que afloran en los alrededores de Tacna (e.g., cerros Acirume, Chuschuco, Los Cóndores, Magollo, Churcos, entre otros) se pueden correlacionar con las que yacen en el subsuelo.

- La integración del análisis de minerales pesados y las correlaciones estratigráficas entre las diferentes unidades permite interpretar la ocurrencia de desplazamientos verticales de alto ángulo (de al menos $200 \mathrm{~m}$ ) que suceden bajo el suelo de Tacna y La Yarada (líneas punteadas negras en las Figs. 4, 5 y 6). Se interpreta también que la presencia de tales desplazamientos verticales tiene una fuerte influencia en la distribución de las facies sedimentarias definidas en este estudio y en la actual morfología.

- En las figuras 11 y 14 se plantea una relación muy notoria entre los sedimentos del sur del Perú (provincias de Moquegua y Arequipa) y los del norte de Chile en cuanto a proveniencia y pulsos de levantamientos sistemáticos de los bordes de cuenca y altos geomorfológicos (e.g., cordillera Occidental).

\section{Agradecimientos}

Los autores agradecen al Instituto Geológico Minero y Metalúrgico (INGEMMET, Perú) y al FONDECYT (CIENCIACTIVA, Perú) por financiar las investigaciones presentadas en el presente manuscrito a través del Convenio N²16-2015 (POI GR41 A 2015-2016). También a J. Jacay (UNMSM), H. Acosta (Lima) y R. Rodríguez (Lima) por compartir fructíferas discusiones que ayudaron al desarrollo del estudio y al Proyecto Especial Tacna (PET, Gobierno Regional de Tacna) por proveer muestras procedentes de los pozos de perforación ubicados en Tacna y La Yarada. Espacial valoración al apoyo entregado por Á. Salas (UNDAC) en los trabajos de campo, y a la contribución de M. Bustamante, D. Barzola, M. Mogrovejo y E. Loaiza (INGEMMET) en la gestión y en la separación de minerales pesados en los laboratorios del INGEMMET. 
Los autores están especialmente agradecidos con W. Vivallo (Santiago de Chile), A. Encinas (Universidad de Concepción, Chile) y C. Gómez (Santiago de Chile) por sus acertadas observaciones.

\section{Referencias}

Acosta, J. 2004. Facies y ambientes sedimentarios de la Formación Moquegua Superior en los alrededores de la ciudad de Tacna. Nuevas contribuciones del IRD y sus contrapartes al conocimiento geológico del sur del Perú. Sociedad Geológica del Perú, Boletín 5: 183-186.

Acosta, J.; Marocco, R.; Quispe, R. 2002. Facies y ambientes sedimentarios de la parte proximal de una cuenca de antearco: el Grupo Moquegua (Dpto. de Moquegua) resultados preliminares. In Congreso Peruano de Geología, No. 11, Sociedad Geológica del Perú, Resúmenes Extendidos: 10 p. Lima.

Acosta, H.; Alván, A.; Mamani, M.; Rodríguez, J. 2011. Geología de los Cuadrángulos de Pachía (36-v) y Palca (36-x) (dos mapas). Instituto Geológico Minero y Metalúrgico, Dirección de Geología Regional, Carta Geológica Nacional, Boletín 139, Serie A: 96 p. Lima.

Acosta, H.; Alván, A.; Mamani, M.; Rodríguez, J.; Cutipa, M. 2012. Geología de los Cuadrángulos de La Yarada, Tacna y Huaylillas, Hojas 37-u, 37-v y 37-x (tres mapas). Escala 1:50.000. Instituto Geológico Minero y Metalúrgico, Dirección de Geología Regional, Carta Geológica Nacional, Boletín 45, Serie A: 114 p. Lima.

Alván, A.; Von Eynatten, H.; Dunk1, I.; Gerdes, A. 2015. Zircon U-Pb geochronology and heavy mineral analysis of the Camaná Formation, southern Perú (16²5’S to $\left.17^{\circ} 15^{\prime} \mathrm{S}\right)$ : constraints to sediment provenance and exhumation of the Coastal and Western cordilleras. Journal of South American Earth Sciences 61: 14-32.

Alván, A.; Jacay, J.; Von Eynatten, H.; Dunkl, I.; Bustamante, Y. 2017a. Arquitectura Estratigráfica Onshore-Offshore de la Cuenca Cenozoica Camaná-Mollendo (Antearco Externo del Sur de Perú): Implicancias en la Exploración de Hidrocarburos. Boletín de la Sociedad Geológica del Perú 112: 78-102.

Alván, A.; Ramírez, K.; von Eynatten, H.; Dunkl, I.; Jacay, J.; Bertone, G. 2017b. Evolución Geológica de las Cuencas de Antearco del Sur de Perú (Moquegua y Camaná-Mollendo): Proveniencia Sedimentaria y Análisis de Facies en Rocas Cenozoicas. Boletín de la Sociedad Geológica del Perú 112: 53-77.

Alván, A.; Jacay, J.; Caracciolo, L.; Sánchez, E.; Trinidad, I. 2018. Facies Analysis of the Mesozoic clastic rocks in Southern Peru (Tacna, $18^{\circ} \mathrm{S}$ ): Towards a
Paleoenvironmental Redefinition and Stratigraphic Reorganization. Journal of South American Earth Sciences 84: 399-421.

Becerra, I. 2017. Caracterización estructural de la Cuenca Mesozoica Arequipa en Pachía (36v) y Palca (36x) mediante análisis microtectónico e integración con información sísmica del subsuelo. Tesis de Ingeniero Geólogo (Inédito), Universidad Nacional de Cajamarca, Perú: 199 p.

Bellido, E. 1969. Sinopsis de la geología del Perú. Comisión de la Carta Geológica Nacional (CCGN), INGEMMET, Perú. Carta Geológica Nacional, Boletín 22, Serie A: 54 p. Lima.

Bellido, E. 1975. Geología del Cuadrángulo de Moquegua, Hoja 35-u. Instituto Geológico Minero y Metalúrgico, Comisión de la Carta Geológica Nacional, Carta Geológica Nacional, Boletín 15, Serie A: 78 p. Lima.

Bellido, E.; Narváez, S. 1960. Geología del Cuadrángulo de Atico, Hoja 33-o. Instituto Geológico Minero y Metalúrgico, Dirección de Geología Regional, Comisión de la Carta Geológica Nacional, Boletín 2, Serie A: p. 59. Lima.

Bellón, H.; Lefévre, C. 1976. Données géochronometriques sur le volcanisme andin dans le sud du Pérou. Implications volcano tectoniques. Comptes Rendus de l'Académie des Sciences, Serie D, Sciences Naturelles 283 (1): 1-4.

Benavides, V. 1999. Chapter 3: Orogenic Evolution of the Peruvian Andes: The Andean Cycle. In Geology and Ore Deposits of the Central Andes (Skimer, B.; editor). Society of Economic Geologists, Special Publication 7: 61-108.

Benites, A. 2017. Variaciones del nivel del mar y cronozonas de ammonites Jurásicos en el sur de la Cuenca Arequipa (Sur de $17^{\circ} \mathrm{S}$ ) Perú: Esquema evolutivo.Tesis de Ingeniero Geólogo (Inédito), Universidad Nacional de Piura: 181 p. Perú.

Bernet, M.; Garver, J.I. 2005. Fission-track Analysis of Detrital Zircon. Reviews in Mineralogy and Geochemistry 58: 205-238.

Bowring, S.A.; Schmitz, M.D. 2003. Chapter 11: Highprecision $\mathrm{U}-\mathrm{Pb}$ zircon geochronology and the stratigraphic record. In Zircon (Hanchar, J.M.; Hoskin, P.W.O.; editores). Reviews in Mineralogy and Geochemistry 53: 305-326.

Bustamante, Y. 2017. Procedencia Sedimentaria de Depósitos Cenozoicos en Base a Análisis de Minerales Pesados en Pachía (36v) y Tacna (37v), Tacna. Tesis de Ingeniero Geólogo (Inédito), Universidad Nacional de Cajamarca: 172 p. Perú. 
Decou, A.; Von Eynatten, H.; Mamani, M.; Sempere, T.; Wörner, G. 2011. Cenozoic forearc basin sediments in Southern Peru $\left(15-18^{\circ} \mathrm{S}\right)$ : Stratigraphic and heavy mineral constraints for Eocene to Miocene evolution of the Central Andes. Sedimentary Geology 237: 55-72.

Decou, A.; Von Eynatten, H.; Dunk1, I.; Wörner, G. 2013. Late Eocene to Early Miocene Andean uplift inferred from detrital zircon fission track and $\mathrm{U}-\mathrm{Pb}$ dating of Cenozoic forearc sediments (15-18 $\left.{ }^{\circ} \mathrm{S}\right)$. Journal of South American Earth Sciences 45: 6-23.

Dickinson, W.W.; Gehrels, G.E. 2009. Use of U-Pb ages of detrital zircons to infer maximum depositional ages of strata: A test against a Colorado Plateau Mesozoic database. Earth and Planetary Science Letters 288: 115-125.

Dunkl, I.; Székely, B. 2002. Component analysis with visualization of fitting-PopShare, a windows program for data analysis. Goldschmidt conference abstracts 2002. Geochimica et Cosmochimica, Acta 66 (15A): p. 201.

Evenstar, L.A.; Mather, A.E.; Hartley, A.J.; Stuart, F.M.; Sparks, R.S.J.; Cooper, F.J. 2017. Geomorphology on geologic timescales: Evolution of the late Cenozoic Pacific paleosurface in Northern Chile and Southern Peru. Earth-Science Reviews 171: 1-27.

Flores, A. 2004. Avances sobre la historia geológica de la Región de Tacna : Sedimentología de la Unidad Magollo (Mioceno medio y/o superior). Nuevas contribuciones del IRD y sus contrapartes al conocimiento geológico del sur del Perú, Boletín 5: 187-194.

Flores, A.; Sempere, T. 2002. Avances en la historia geológica del valle de Tacna. In Congreso Peruano de Geología, No. 11, Sociedad Geológica del Perú, Resúmenes Extendidos: 22 p. Lima.

Flores, A.; Sempere, T.; Fornari, M. 2004. Síntesis actualizada de la estratigrafía del Cenozoico en el extremo sur del Perú. In Congreso Peruano de Geología, No. 12, Resúmenes Extendidos: 346-352. Lima.

France, L.J.; Clark, A.H.; Farrar, E. 1984. Geochonological and petrological studies of Tertiary igneous rocks, Cordillera Occidental, southernmost Peru: a preliminary report. Instituto Geológico Minero y Metalúrgico, Reporte Interno: 28 p. Lima.

García, M.; Gardeweg, M.; Clavero, J.; Hérail, G. 2004. Hoja Arica, Región de Tarapacá. Servicio Nacional de Geología y Minería, Carta Geológica de Chile, Serie Geología Básica 84: 150 p., 1 mapa escala 1:250.000. Santiago

Garzione, C.N.; Hoke, G.D.; Libarkin, J.C.; Withers, S.; MacFadden, B.; Eiler, J.; Ghosh, P.; Mulch, A. 2008. Rise of the Andes. Science 320 (5881): 1304-1307.
Gregory-Wodzicki, K.M. 2000. Uplift history of the Central and Northern Andes: A review. Geological Society of America Bulletin 112 (7): 1091-1105.

Haschke, M.; Günther, A.; Melnick, D.; Echtler, H.; Reutter, K.J.; Scheuber, E.; Oncken, O. 2006. Chapter 16: Central and South Andean Tectonic Evolution Inferred from Arc Magmatism. In The Andes, Active Subduction Orogeny (Oncken, O.; Chong, G.; Franz, G.; Giese, P.; Götze, H.-J.; Ramos, V.A.; Strecker, M.R.; Wigger, P.; editors). Springer-Verlag Berlin Heidelberg: 337-349. Berlin.

Horton, B.K. 2018. Sedimentary record of Andean mountain building. Earth-Science Reviews 178: 279-309.

Horton, B.K.; Gillis, R.J.; Farley, K.A.; Wörner, G. 2007. Kinematic evolution of the central Andean fold-thrust belt and hinterland plateau inferred from synorogenic strata and low-temperature thermochronology. In Geological Society of London, Continental Tectonics and Mountain Building, Specialty Meeting, Abstract: 4 p. Berlin.

Hubert, J.F. 1962. A Zircon-Tourmaline-Rutile maturity index and the interdependence of the composition of heavy mineral assemblages with the gross composition and texture of sandstones. Journal of Sedimentary Petrology 32 (3): 440-450.

Isacks, B.L. 1988. Uplift of the Central Andean plateau and bending of the Bolivian orocline. Journal of Geophysical Research 93: 3211-3231.

Jaén, H.; Ortiz, G. 1963. Geología de los Cuadrángulos de La Yarada y Tacna (Hojas 37-u y 37-v). Instituto Geológico Minero y Metalúrgico, Dirección de Geología Regional, Comisión Carta Geológica Nacional, Boletín 6, Serie A: 54 p. Lima.

Jordan, T.E.; Isacks, B.L.; Allmendinger, R.W.; Brewer, J.A.; Ramos, V.A.; Ando, C.J. 1983. Andean tectonics related to geometry of subducted Nazca plate. Geological Society of America Bulletin 94 (3): 341-361.

Ludwig, K.R. 2003. User's Manual for Isoplot 3.00: a Geochronological Toolkit for Microsoft Excel. Berkeley Geochronology 4. Center Special Publication: 70 p.

Madella, A.; Delunel, R.; Audin, L.; Schlunegger, F.; 2018. Why is there no Coastal Cordillera at the Arica Bend (Western Central Andes)? Basin Research 30 (1): 248-268.

Mahlburg-Kay, S.; Mpodozis, C. 2002. Magmatism as a probe to the Neogene Shallowing of the Nazca plate beneath the modern Chilean flat-slab. Journal of South American Earth Sciences 15: 39-57.

Mahlburg-Kay, S.; Godoy, E.; Kurtz, A. 2005. Episodic arc migration, crustal thickening, subduction erosion, and magmatism in the south-central Andes. Geological Society of America Bulletin 117 (1-2): 67-88. 
Mamani, M.; Wörner, G.; Sempere, T. 2010. Geochemical variations in igneous rocks of the Central Andean orocline $\left(13^{\circ} \mathrm{S}\right.$ to $\left.18^{\circ} \mathrm{S}\right)$ : Tracing crustal thickening and magma generation through time and space. Geological Society of America 122: 162-182.

Mamani, M.; Rodríguez, R.; Acosta, H.; Jaimes, F.; Navarro, P.; Carlotto, V. 2012. Características Litológicas y Geoquímicas más Resaltantes de los Arcos Magmáticos del Perú desde el Ordovícico. In Congreso Peruano de Geología, No. 16, Sociedad Geológica del Perú, Resúmenes Extendidos: 5 p.

Mange, M.A.; Maurer, H.F.W. 1992. Heavy Minerals in Colour. Chapman and Hall: 147 p. London.

Mange, M.A.; Dewey, J.F.; Wright, D.T. 2003. Heavy minerals solve structural and stratigraphic problems in Ordovician strata of the western Irish Caledonides. Geological Magazine 140 (1): 25-30.

Marocco, R.; Noblet, C. 1990. Sedimentation, tectonism and volcanism relationships in two Andean basins of southern Peru. Geologische Rundschau 79 (1): 111-120.

Marocco, R.; Delfaud, J.; Lavenu, A. 1985. Ambiente deposicional de una cuenca continental intramontañosa andina: el Grupo Moquegua (sur de Perú) primeros resultados. Sociedad Geológica del Perú 75: 73-90.

Martínez, C.; Vargas, R.; Montoya, J.; Chamorro, C.; Zenteno. E. 1996. Estudio hidrogeológico de las pampas de La Yarada y Hospicio, Tacna. Ministerio de Agricultura, Instituto Nacional de Recursos Naturales. Informe Técnico 8: 45 p. Lima.

Miall, A.D. 1996. The Geology of Fluvial Deposits: Sedimentary Facies, Basin Analysis, and Petroleum Geology. Springer-Verlag: 582 p. New York.

Miall, A.D. 2014. Fluvial Depositional Systems. Springer: 322 p. Berlin.

Monge, R.; Cervantes, J. 2000. Memoria explicativa de la Geología del Cuadrángulo de Pachía y Palca (36-v). Instituto Geológico Minero y Metalúrgico: 11 p. Lima.

Morton, A.C.; Hallsworth, C.R. 1999. Processes controlling the composition of heavy mineral assemblages in sandstones. Sedimentary Geology 124: 3-29.

Narváez, S. 1964. Geología de los cuadrángulos de Ilo (36t) y Locumba (36u). Instituto Geológico Minero y Metalúrgico, Dirección de Geología Regional, Carta Geológica Nacional, Boletín 7, Serie A: 75 p.

Nemec, W.; Steel, R.J. 1984. Alluvial and Coastal Conglomerates: Their Significant Features and Some Comments on Gravelly Mass-Flow Deposits. In Sedimentology of Gravels and Conglomerates Canadian Society of Petroleum Geologists (Kosler, E.; Steel, R.J.; editores). Memoir 10: 1-31.
Noble, D.; Sébrier, M.; Mégard, F.; McKee, E. 1985. Demonstration of two pulses of Paleogene deformation in the Andes of Peru. Earth and Planetary Science Letters 73: 345-349.

Noury, M.; Philippon, M.; Bernet, M.; Paquette, J.L.; Sempere, T. 2017. Geological record of slab-induced extension in the southern Peruvian forearc. Geological Society of America 45 (8): 723-726.

Oncken, O.; Hindle, D.; Kley, J.; Elger, K.; Victor, P.; Schemmann, K. 2006. Chapter 1: Deformation of the Central Andean Upper Plate System-Facts, Fiction, and constrains for the Plateau Models. In The Andes, Active Subduction Orogeny (Oncken, O.; Chong, G.; Franz, G.; Giese, P.; Götze, H.J.; Ramos, V.A.; Strecker, M.R.; Wigger, P.; editores). Springer-Verlag Berlin Heidelberg: 1-27. Berlin.

PERUPETRO. 2003. Peruvian Petroleum, A Renewed exploration opportunity. Informe Técnico, PERUPETRO S.A.: 159. Lima.

PET, 2007. Informe de Avance: Análisis de la Línea Base Geofísica. Proyecto "Afianzamiento de los Recursos Hídricos de Tacna”, Actividad: “Compatibilización de los Estudios Hidrogeológicos del Reservorio Acuífero La Yarada". Meta 00782: Estudios Básicos para el Manejo de Cuencas. Informe Técnico, Proyecto Especial Tacna (PET): 113 p.

Palacios, O.; Castillo, M. 1983. Compendio estratigráfico del Jurásico-Cretáceo en el Perú, Faja Costanera y Andina. Revista de la Sociedad Geológica del Perú, Boletín 71: 263-277.

Palacios, O.; De la Cruz, J.; De la Cruz, N.; Klinck, B.; Ellison, R.; Hawkins, M.P. 1993. Geología de la Cordillera Occidental y Altiplano al Oeste del Lago Titicaca-Sur del Perú. Proyecto Integrado del Sur. Instituto Geológico Minero y Metalúrgico, Carta Geológica Nacional, Boletín 42, Serie A: 257 p. Lima.

Petersen, U. 1958. Structure and uplift of the Andes of Peru, Bolivia, Chile and adjacent Argentina. Sociedad Geológica del Perú, Boletín 33: 57-218.

Quang, C.; Clark, A.; Lee, J.K.; Hawkes, N. 2005. Response of supergene processes to episodic Cenozoic uplift, pediment erosion, and ignimbrite eruption in the porphyry copper province of southern Peru. Economic Geology 100: 87-110.

Reiners, P.W.; Ehlers, T.A.; Zeitler, P.K. 2005. Chapter 1: Past, Present, and Future of Thnermochronology. In Low-Temperature Thermochronology: Tecniques, Interpretations, and Applications Reiners (Reiners, P.W.; editores). Reviews in Mineralogy and Geochemistry 58: 1-18. 
Salas, R.; Kast, R.F.; Montesinos, F.; Salas, I. 1966. Geología y recursos minerales del departamento de Arica (Chile). Instituto de Investigaciones Geológicas. Boletín 21: 174 p. Santiago.

Salinas, J.; Chambilla, W. 2005. Perforación Exploratoria Diamantina del Pozo TDRY-01. Afianzamiento y Ampliación de los Recursos de Tacna: Gestión de Estudios y Proyectos. Informe Técnico Final, Meta 01851 (Elaboración de Estudios Básicos). Proyecto Especial Tacna (PET): 44 p.

Salinas, J.; Chambilla, W. 2006. Perforación Exploratoria Diamantina del Pozo TDRY-02. Afianzamiento y Ampliación de los Recursos de Tacna: Gestión de Estudios y Proyectos. Informe Técnico 300695, Meta 01851 (Elaboración de Estudios Básicos). Proyecto Especial Tacna (PET): 68 p.

Sánchez, A.; Rosell, W.; Raymundo, T. 2000. Memoria explicativa de la revisión geológica en los cuadrángulos de Punta del Bombón (35s), La Clemesí (35t), Ilo (36t), Locumba (36u), La Yarada (37u), Tacna (37v), Huaylillas (37x), Juli (33y), Pizacoma (34y) e Isla Anápia (33z). Franja 1. Memoria Descriptiva. Instituto Geológico Minero y Metalúrgico, Dirección de Geología Regional: 40 p. Lima.

Sempere, T.; Jacay, J. 2008. Anatomy of the Central Andes: Distinguishing between western, magmatic Andes and eastern, tectonic Andes. In International Symposium on Andean Geodynamics, No. 7. Extended abstracts: 504-507. Nice.

Sempere, T.; Fornari, M.; Acosta, J.; Flores, A.; Jacay, J.; Pena, D.; Roperch, P.; Taipe, E. 2004. Estratigrafía, geocronología y paleotectónica de los depósitos de antearco del sur del Perú. In Congreso Peruano de Geología, No. 12, Sociedad Geológica del Perú, Resúnemes Extendidos: 366-372.

Sempere, T.; Noury, M.; García, F.; Bernet, M. 2014. Elementos para una actualización de la Estratigrafía del Grupo Moquegua, sur del Perú. In Congreso Peruano de Geología, No. 17, Sociedad Geológica del Perú, Resúmenes Extendidos: 4 p.

Thouret, J.C.; Wörner, G.; Gunnell, Y.; Singer, B.; Zhang, X.; Souriot, T. 2007. Geochronologic and stratigraphic constrains on canyon incision and Miocene uplift of the Central Andes in Peru. Earth and Planetary Science Letters 263: 151-166.

Tosdal, R.M.; Farrar, E.; Clark, A. 1981. K-Ar Geochronology of the Late Cenozoic volcanic rocks of the Cordillera Occidental, Southernmost Peru.
Journal of Volcanology and Geothermal Research 10: 157-173.

Trinidad, I. 2017. Evolución Geodinámica del Mesozoico al Sur de la Cuenca Arequipa en el Sur del Peru $\left(17^{\circ}-18^{\circ} \mathrm{S}\right.$ Latitud Sur) Basado en Análisis de Minerales Pesados. Tesis de Ingeniero Geólogo (Inédito), Universidad Nacional Daniel Alcides Carrión: 108 p. Perú

Vargas, L. 1970. Geología del Cuadrángulo de Arequipa. Dirección de Geología Regional, INGEMMET, Perú, Boletín 24, Serie A: Carta Geológica Nacional: 64 p. Vatin-Perignon, N.; Poupeau, G.; Oliver, R.A.; Lavenu, A.; Labrin, F.; Keller, F.; Bellot-Gurlet, L. 1996. Trace and rare-earth element characteristics of acidic tuffs from Southern Peru and Northern Bolivia and a fission-track age for the Sillar of Arequipa. Journal of South American Earth Sciences 9: 91-109.

Vermeesch, P. 2012. On the visualisation of detrital age distributions. Chemical Geology 312-313: 190-194.

Vicente, J.C.,1981. Elementos de la estratigrafía Mesozoica sur Peruana. In Cuencas sedimentarias del jurásico y cretácico de América del sur (Volkheimer, I.; Musacchio, A.; editores). Comité Sudamericano del Jurásico y Cretácico 1: 319-351. Buenos Aires.

Wilson, J.; García, W. 1962. Geología de los Cuadrángulos de Pachía y Palca (Hojas 36-v y 36-x). Ministerio de Fomento, Dirección de Minería, Boletín 4, Serie A, Comisión de la Carta Geológica Nacional: 82 p. Perú. Wörner, G.; Hammerschmidt, K.; Henjes-Kunst, F.; Lezaun, J.; Wilke, H. 2000. Geochronology $\left({ }^{40} \mathrm{Ar} /{ }^{39} \mathrm{Ar}\right.$, $\mathrm{K}-\mathrm{Ar}$ and He-exposure ages) of Cenozoic magmatic rocks from Northern Chile $\left(18-22^{\circ} \mathrm{S}\right)$ : implications for magmatism and tectonic evolution of the central Andes. Revista Geológica de Chile 27 (2): 205-240. doi: 10.5027/andgeoV27n2-a04.

Wörner, G.; Uhlig, D.; Kohler, I.; Seyfried, H. 2002. Evolution of the West Andean Escarpment at $18^{\circ} \mathrm{S}$ (N. Chile) during the last $25 \mathrm{Ma}$ : uplift, erosion and collapse through time. Tectonophysics 345: 183-198.

Wotzlaw, J.F.; Decou, A.; von Eynatten, H.; Wörner, G.; Frei, D. 2011. Jurassic to Paleogene tectono-magmatic evolution of northern Chile and adjacent Bolivia from detrital zircon $\mathrm{U}-\mathrm{Pb}$ geochronology and heavy mineral provenance. Terra Nova: 1-8.

Zenteno, E.; Pérez, E.; Gamarra, J.; Curo, M.; Paiva, L. 2003. Estudio Hidrogeológico del Valle Caplina. Evaluación y Ordenamiento de los Recursos Hídricos en la Cuenca del Río Caplina. Instituto Nacional de Recursos Naturales, Intendencia de Recursos Hídricos. Informe Técnico: 225 p.

Manuscript received: February 1, 2018; revised/accepted: June 18, 2019; available online: January 31, 2020. 